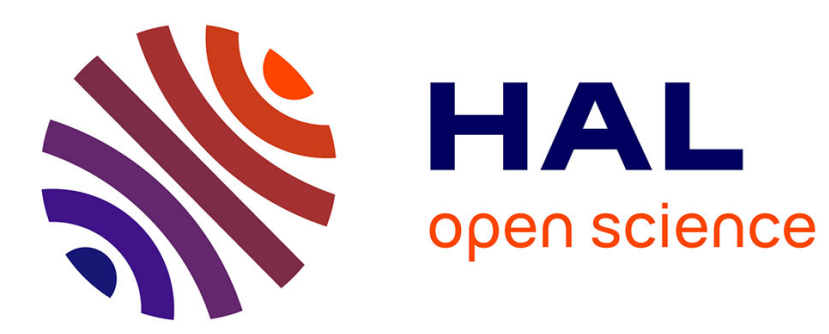

\title{
Numerical investigation of airflow through a Savonius rotor
}

\author{
Placide Jaohindy, Habiba Ennamiri, François Garde, Alain Bastide
}

\section{To cite this version:}

Placide Jaohindy, Habiba Ennamiri, François Garde, Alain Bastide. Numerical investigation of airflow through a Savonius rotor. Wind Energy, 2014, 17 (6), pp.853-868. 10.1002/we.1601 . hal-00917857

\section{HAL Id: hal-00917857 \\ https://hal.science/hal-00917857}

Submitted on 28 Oct 2017

HAL is a multi-disciplinary open access archive for the deposit and dissemination of scientific research documents, whether they are published or not. The documents may come from teaching and research institutions in France or abroad, or from public or private research centers.
L'archive ouverte pluridisciplinaire HAL, est destinée au dépôt et à la diffusion de documents scientifiques de niveau recherche, publiés ou non, émanant des établissements d'enseignement et de recherche français ou étrangers, des laboratoires publics ou privés. 


\title{
Numerical investigation of airflow through a Savonius rotor
}

\author{
P. Jaohindy, H. Ennamiri, F. Garde, A. Bastide \\ Physics and Mathematical Engineering Laboratory for Energy and Environment (PIMENT), University of Reunion Island, South \\ Campus, 117 Avenue du Général Ailleret, 97430, Le Tampon, France.
}

\begin{abstract}
The aim of this report is to present a model of a rigid-rotor system based on computational fluid dynamics (CFD), which is applied on a vertical axis wind turbine (VAWT) research. Its originality results from the use of the average value of the variable rotational speed method taken in a periodic steady-state (PSS) of the VAWT rotor instead of the classical fixed rotational speed method. This approach was chosen in order to determine the mechanical and aerodynamic parameters of the wind turbine. The modeling method uses an implicit Euler iterative solution strategy which resolves the coupling between fixed and moving rotor domains. The main methods that were adopted are based on the three-dimensional modeling of the interaction of the fluid flow with a rigid-rotor. The strategy consists of using the Reynolds averaged Navier Stokes (RANS) equations with the standard k- $\varepsilon$ and SST k- $\omega$ models to solve the fluid flow problem. To perform the rigid-rotor motion in a fluid, the one degree of freedom (1-DOF) method was applied. In the present study, the steadystate and dynamic CFD simulations of the Savonius rotor are adopted to contribute to the validation elements of the VAWT models that are used. The dynamic study allows the investigation of the rotor behavior and the relation between velocity, pressure, and vorticity fields in and around the rotor blades. The flow fields generated by the rotation of the Savonius rotor were investigated in the half revolution period of the rotor angle $\theta$ from 0 to $180 \mathrm{deg}$. In this range of $\theta$, the focus is on generating and dissipating vortices. Copyright (c) 2012 John Wiley \& Sons, Ltd.
\end{abstract}

\section{KEYWORDS}

VAWT; Savonius rotor; 1-DOF; Rigid-rotor; CFD; Vortex analysis.

\section{Correspondence}

Placide Jaohindy, University of Reunion Island, 117 Avenue du Général Ailleret, 97430, Le Tampon, France 
Tel.: +262 6926000 72; Fax: +262 2625794 46; E-mail: placide.jaohindy@univ-reunion.fr

\section{Contract/grant sponsor}

This work was partially supported by European Union (EU) and the Regional Council of Reunion Island.

Received ...

\section{NOMENCLATURE}

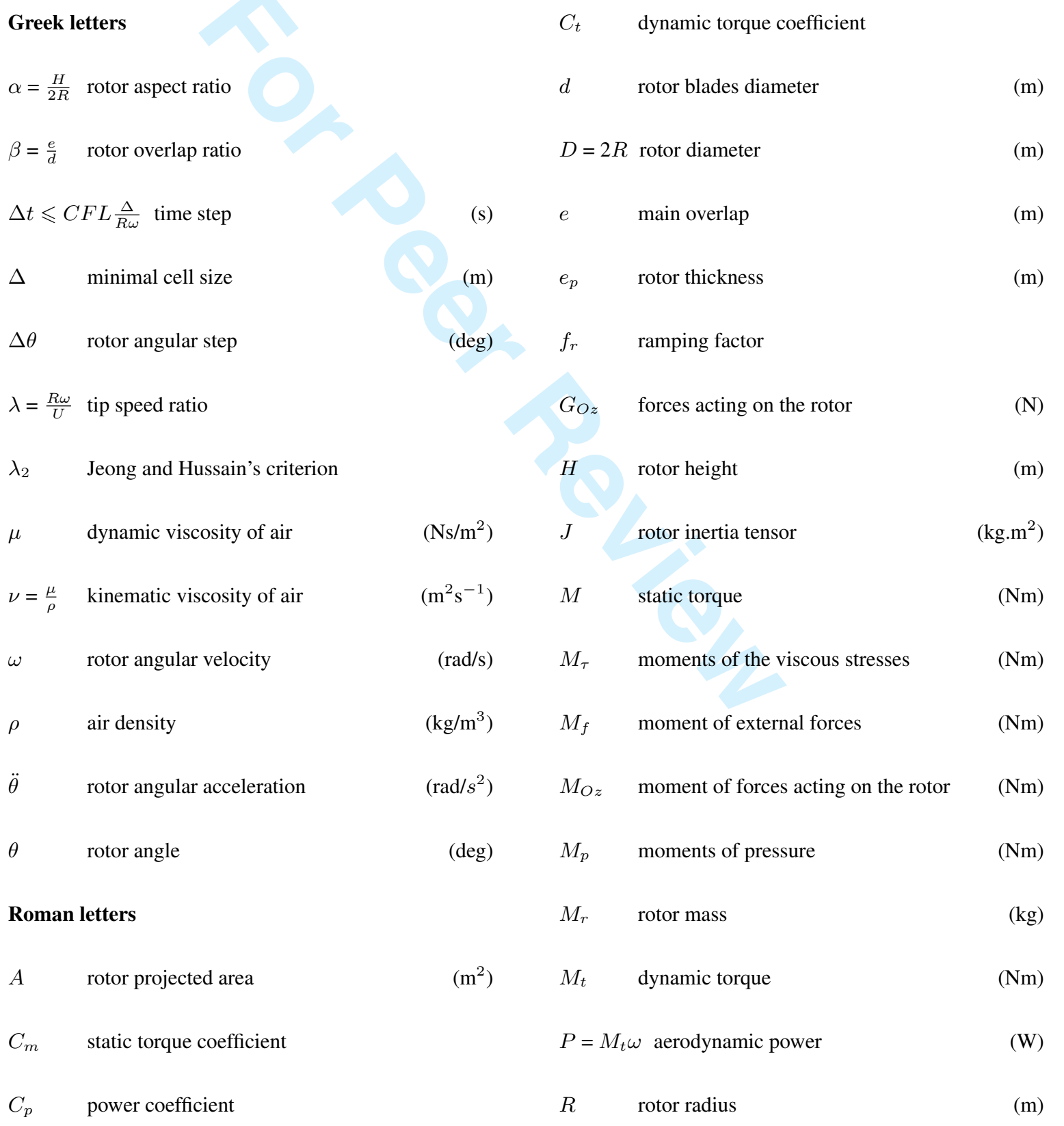


P. Jaohindy et al.

Re Reynolds number

T computational time

$U \quad$ free stream velocity
Numerical investigation of airflow through a Savonius rotor

$\begin{array}{ccc} & v & \text { axial velocity } \\ \text { (s) } & v^{\prime}=\frac{v}{U} & \text { dimensionless axial velocity } \\ (\mathrm{m} / \mathrm{s}) & y^{+} & \text {dimensionless wall distance }\end{array}$

\section{INTRODUCTION}

The Savonius rotor is a vertical axis wind turbine (VAWT) that was originally invented by the Finnish engineer Sigurd J. Savonius in 1922 [1]. The concept of a Savonius rotor consists of the principle formulated by Anton Flettner and Savonius [1]. It is formed by two semi-circular blades where the main axis is perpendicular to the wind direction and it accepts wind with any incidence without loss of performance. The Savonius rotor's operation is based on the differential drag between its two blades. The drag is the resistance generated by the fluid on the Savonius rotor blades and vice versa. Chauvin and Benghrib [2] studied the lift and drag coefficients of a Savonius rotor with a tip speed ratio $\lambda$ ranging from 0.2 to 1 . They found that the drag coefficient of this rotor is always negative and the lift coefficient is negative for a low value of $\lambda$. The Savonius rotor is usually considered to be a drag machine, but Modi and Fernando [3] and Kamoji et al. [4] defend that it is a combination of a lift and a drag machine. Hence, at low angles of attack, the lift force contributes to torque production [4]. The Savonius rotor is a slow running VAWT that starts at low wind speeds of 2 to $3 \mathrm{~m} / \mathrm{s}$. A large number of investigations have been conducted to identify the aerodynamic parameters of this wind turbine. Le Gourières [5] studied the geometrical parameters that affect the low efficiency of the basic Savonius rotor of $20 \%$. One of these parameters is the rotor aspect ratio $\alpha$ [1,5]. For the conventional Savonius rotor of Ushiyama and Nagai [6], it was suggested that $\alpha=4$. This rotor can reach a maximum power coefficient $C_{p}$ of $30 \%$ and an average static torque coefficient $C_{m}$ of $33 \%$, with a rotor overlap ratio $\beta$ between 0.2 to 0.3 [6]. In a two-dimensional study of a conventional rotor, Menet et al. $[7,8]$ found that the optimal value of $\beta$ is 0.242 . Before the Ushiyama and Nagai [6] investigations, Blackwell et al. [9] performed several tests on the geometrical parameters of the Savonius rotor. Blackwell et al. [9] studied the performance of fifteen configurations of a Savonius rotor in wind tunnel conditions. The study by Blackwell et al. [9] varied the dynamic torque $C_{t}$ and the power cofficient $C_{p}$ as functions of the tip speed ratio $\lambda$, the rotor overlap ratio $\beta$, and the Reynolds number Re. The $C_{p}$ obtained by the three-blade Savonius rotor was 0.18 at $\beta=0.10$. For the same $\beta$, the maximum dynamic torque coefficient $C_{t}$ obtained with a two-blade Savonius rotor is 0.35 . They pointed out that increasing the $R e$ number intensifies the performance of the Savonius rotor. The three-bladed Savonius rotor is known for its good starting torque [10]. Blackwell et al. [9] recommended the use of a Savonius rotor with two-blades and a $\beta$ 
between 0.1 to 0.5 [6]. The Savonius rotor of Run 35 and 37 of Blackwell et al. [9] was used in the present study because the uncertain analysis of the $C_{t}$ and $C_{p}$ curves was measured in their experiments. The rotors used both cases tests are identical. The research based on the two-stages Savonius rotor shows that the starting torque coefficient of the rotor is never negative and it presents a good angular stability of the dynamic torque $M_{t}$ [11]. To clarify the effect of $\beta$ on the flow mechanism, Fujisawa studied the flow fields in and around Savonius rotors at various $\beta$ in a water channel. Fujisawa compared the obtained experimental results with a two-dimensional numerical study using the discrete vortex method [12]. The numerical investigations made by Fujisawa assumed that the studied problem was a high Reynolds number flow. Fujisawa concluded that the two-dimensional simulation approach of the flow is not valid. The numerical study of a Savonius rotor had to be run in a three-dimensional approach to have a better representation of the three-dimensional vortical structures around the rotor [12]. The importance of the three-dimensional properties of the fluid flow in a case of a Savonius rotor bring us to lead this study in three-dimensions.

Wind energy problems involving airflow in and around a VAWT have traditionally been studied through wind tunnel testing facilities $[3,9]$. Computational Fluid Dynamics (CFD) techniques were used instead of a wind tunnel in order to make tests for several reasons. Wind tunnel experiments are expensive and the techniques used to visualize the flow fields are costly. It was suggested that the CFD methods predict the flow around a VAWT rather accurately for the objectives of this work [13].

The aims of this article are:

- To validate the developed numerical models based on the steady-state CFD simulation analysis and a solid-fluid coupling;

- To develop an approach to the study of a Savonius VAWT, which is based on the variable rotational speed method.

Few authors have opted for the variable rotational speed method applied to Savonius wind turbine modeling [14]. Indeed, the constant rotational speed method is more regularly used to study the Savonius wind turbine rotor [7, 15]. However, a variable rotational speed method allows the new creation of a real Savonius rotor rotation by integrating its governing equation. The internal region concept at the interface between the two computational domain regions used in the sliding mesh method will shortly be described. Steady-state and dynamic studies have been conducted with the standard k- $\varepsilon$ and SST k- $\omega$ models. Experimental studies of the Savonius rotor are in keeping with the steady-state simulation results. The dynamic study allows the identification of the mechanical behavior of the Savonius rotor and the flow fields around it. The analysis of the three fields of velocity, pressure, and vorticity are discussed. 


\section{SIMULATION OF A VAWT}

\subsection{Numerical method}

In this study, the three-dimensional RANS equations were discretized in the computational domain by the finite volume method. The time integration was calculated by the implicit Euler scheme. This integration gives a temporal variation of the dynamic parameters in the simulation using the 1-DOF method. Two turbulence models for RANS closure were implemented: the standard $\mathrm{k}-\varepsilon$ and SST $\mathrm{k}-\omega$ models $[16,17]$. The standard $\mathrm{k}-\varepsilon$ model is also known as a two equation model and is derived from the linear eddy viscosity model. With the standard $\mathrm{k}-\varepsilon$ model approach, two transport equations are used to solve the Reynolds stress tensor [16]. These two equations are respectively the transport equation for the kinetic energy $k$ and the dissipation rate $\varepsilon$. The standard $\mathrm{k}-\varepsilon$ model is generally used to model a turbulent flow far from the wall [16]. The SST k- $\omega$ is a hybrid model developed by Menter and based on the standard k- $\varepsilon$ and k- $\omega$ models [17]. The Menter's first interest was to improve the performances for adverse pressure gradient (APG) flows, which are found during a flow around a static bluff body, such as VAWT. The second aim was to solve the problem of spurious sensitivity to free-stream conditions [18]. Christopher and Susan [19] argue that the k- $\omega$ model shows poor performance regarding the wall-bounded separated flows caused by the APG [20]. The improvements of the SST k- $\omega$ approach in predicting many aeronautical flows motivate us to use this model in our study. For the standard k- $\varepsilon$ and the SST k- $\omega$ models that were used, a log law function for smooth wall was used. For the classical two models, the maximum of the dimensionless wall distance $y^{+}$is 5 at each simulation.

\subsection{Modeling environment}

\subsubsection{Grid independence test}

A mesh independence test was conducted for the steady-state and dynamic computational domains to improve the accuracy of the CFD results. These two computational domain meshes are then progressively refined until the observed physical quantities were stabilized. They were used to determine the rotor parameters in a steady and unsteady flow. The two computational domains were meshed using Star-CCM+ software. The first one is used for a static simulation and requires a reasonable number of cells, in order to give consistent static values of moments $M$. The second one is used for the moving mesh methods. It is formed by internal and external grids. These two grids are separated by a fixed interface. The moving mesh methods is based on exchanging information at interfaces. The smooth wall boundary condition is assumed. The near wall layers were prismatic elements with triangular bases. The length of the first layer from the blade surface was 
approximately 0.005 . Two layers of prismatic elements were used and less than 1.15 growth ratio. The maximum height of the cells around the walls of the Savonius rotor blades and endplates obtained for $y^{+}$was 5 . The value of $y^{+}$depends on the spatial variations of the rotating flow near the wind turbine rotor wall and the turbulence models.

The mesh independence study is checked by comparing the static torque $M$ loads on the rotor blades. Fine mesh results are obtained with Grids 1, 2, and 3 in Table I for the static computational domain cells. Fine mesh results are also obtained with Grids 1 and 2 for the dynamic computational domain cells.

Table I. Grid independence test for the static and dynamic computational domain

\begin{tabular}{c|cc|cc}
\hline Grids & cells (static) & $M(\mathrm{Nm})$ & cells (dynamic) & $M(\mathrm{Nm})$ \\
\hline Grid1 & 94,139 & 5.712 & 266,201 & 4.71 \\
Grid2 & 77,836 & 5.711 & 242,198 & 4.71 \\
Grid3 & 45,404 & 5.710 & 93,442 & 4.52 \\
Grid4 & 44,921 & 5.683 & 66,147 & 4.40 \\
Grid5 & 38,784 & 5.002 & 51,965 & 4.20 \\
\hline
\end{tabular}

For a given simulation, the number of cells in the chosen computational domain is of great importance for accurate simulation results. This number of cells for grid independence was taken in Table I, where there is no significant variation in the simulated parameter $M$. The computational domain of the steady-state study is composed of 77,836 cells. The minimum polyhedral cell width of this domain $\Delta$ is equal to $0.015 \mathrm{~m}$. The computational domain of the dynamic study comprises 242,198 cells. The minimum polyhedral cell width of this domain $\Delta$ is equal to $0.0074 \mathrm{~m}$. The mesh quality of the dynamic computational domain used in this study is established by an aspect ratio of 20 and a skewness of about 0.85 .

\subsubsection{Computational domain}

The computational domain used in this study (see Figure 1 ) is a parallelepiped of $20 \mathrm{~m} \times 10 \mathrm{~m} \times 3 \mathrm{~m}$ with two regions. A cylinder of $1 \mathrm{~m}$ radius and $3 \mathrm{~m}$ height is placed at the center of this domain. The Savonius rotor is interdependent with the cylindrical region and is placed at a height of $1.5 \mathrm{~m}$ on the rotational axis $O z$. The parallelepiped and the cylindrical regions of the computational domain are geometrically independent from one another. The parallelepiped and the cylinder are centered at $(0,0,1) \mathrm{m}$. The Savonius rotor is centered at $(0,0,1.5) \mathrm{m}$. The cylindrical region rotates through the interface of 4,176 cells. The rotation of the internal region with respect to the parallelepiped region uses a sliding mesh method [21].

Figure 1. Geometrical characteristics of the computational domain. The radius of the internal region of the computational domain is $2.22 R$. The wind flow direction at the computational domain is along the $O x$ axis. 
1

\subsubsection{Geometry of the rotor}

The Savonius rotor used in this study is represented in Figures 2(a) and 2(b) and has the following features: rotor height $H=1 \mathrm{~m}$, rotor radius $R=0.4512 \mathrm{~m}$ and the rotor overlap ratio $\beta=0.2$.

Blackwell et al. [9] have highlighted in their report that the Savonius rotor was made of aluminum alloy type 6060T6. However, there are many different types of aluminum in which densities differ. The density $\rho$ of material of rotor construction is equal to $2700 \mathrm{~kg} / \mathrm{m}^{3}$. knowing $\rho$, we chose to set the thickness $e_{p}$ of the rotor by an inverse method. The initial condition of this method was to fix one point on the experimental curve. The stopping criterion, which gives the thickness of the rotor $e_{p}$, is substantially equal to $0.0021 \mathrm{~m}$, is the convergence of the experimental and the numerical points to the same value. This choice is arbitrary, but this does not affect the continuity of the calculations. Indeed, the thickness and density are involved only to calculate the moment of inertia $J$ and in particular, they are involved to calculate the mass of the rotor. It is necessary to know the moment of inertia $J$ to carry out the integration of the equation of motion of the rotor. In this study, the thickness $e_{p}$ of the rotor is considered as artificial.

The steady-state studies of the Savonius rotor are independent of the rotor thickness $e_{p}$. A $e_{p}$ of $0.01 \mathrm{~m}$ was considered.

\section{(a) (b)}

Figure 2. Sketch and geometric parameters of the Savonius rotor.

\subsubsection{Boundary and initial conditions}

The Reynolds number based on the rotor diameter $D$ is given by

$$
R e=\frac{\rho U D}{\mu}
$$

where Re is the Reynolds number, $\rho$ is the air density, $U$ is the free stream velocity, $D$ is the rotor diameter and $\mu$ is the dynamic viscosity of the air.

In this study, the Reynolds number per metre is given by $R e / \mathrm{m}=4.32 \times 10^{5}$, the air density by $\rho=1.2157 \mathrm{~kg} / \mathrm{m}^{3}$ and the dynamic viscosity of the air by $\mu=1.777 \times 10^{5} \mathrm{Ns} / \mathrm{m}^{2}$. The variation of these two parameters influences the aerodynamic and mechanical parameters of the wind turbine rotor. For the velocity inlet boundary conditions, the free stream velocity $U=7 \mathrm{~m} / \mathrm{s}$. The pressure outlet boundary conditions specify the static pressure at flow outlets. The inlet and outlet boundaries were placed far enough apart to ensure their minimal influence on the flow in the immediate vicinity of the rotor. A slip wall was used for the top, lower, left and right parts of the computational domain. The Savonius rotor is 
made of aluminum with a $\rho$ of $2700 \mathrm{~kg} / \mathrm{m}^{3}$. The rotor mass $M_{r}=17.74 \mathrm{~kg}$ and the component of the rotor inertia tensor $J$ along $O z$ axis $J_{O z}=2 \mathrm{~kg} \cdot \mathrm{m}^{2}$ were analytically estimated.

\subsection{Computational methodology}

In order to achieve the objectives of the study, the results of the three-dimensional steady-state and dynamic simulations were compared to experiments. The standard k- $\varepsilon$ and SST k- $\omega$ models were used to predict the static torque coefficient $C_{m}$, the dynamic torque coefficient, $C_{t}$ and the power coefficient $C_{p}$.

\subsubsection{Resolution methods}

In this study, the steady-state simulation is solved by a direct method. The flow chart in Figure 3 is made of three main processes : the Fluid Resolution process, the Motion Resolution Process and the Mesh rotation process.

Figure 3. Flow chart of the dynamic simulation.

In this section, the aerodynamic parameters and the formulation of the equation of motion for the VAWT rotor are analyzed. The present study was performed by using a CFD solver with steady-state and dynamic simulation capabilities [21]. The motion resolution of a Savonius rotor was obtained by the coupling of the fluid and rigid-rotor equations. This method applied to a two-dimensional numerical investigation of a Savonius rotor was initiated by D'Alessandro et al. $[14,22]$. The method was used in the present study to lead a full three-dimensional numerical investigation of a Savonius rotor. The implicit Euler scheme was used for the dynamic simulation as it is numerically stable in comparison to other schemes. Figure 3 gives the flow chart of the dynamic studies of the Savonius rotor.

In Figure 3, the rotor angle $\theta$ and the rotational velocity $\omega$ parameters have been initialized by $\theta_{0}$ and $\omega_{0}$. At a time $t$, these two parameters are obtained by the integration of Eq. (7) and are carried out in the Motion Resolution process of Figure 3. Both parameters $U$ and $M_{f}$ are used to initialize the Fluid resolution process of Figure 3. From the initial state, the rotor is considered to be stationary and $\omega_{0}=0$. These initial conditions allow each $\Delta t$ to trigger the processes: Fluid Resolution and Motion Resolution of Figure 3. The moments of pressure $M_{p}$ and the moments of the viscous stresses $M_{\tau}$ determined by the Fluid Resolution and the Motion Resolution Process used first the integration of Eq. (7) and the solution of this equation makes it possible to re-calculate the values of $\omega(t)$ and $M_{t}(t)$ of the Savonius rotor. $\Delta t$ depends on $C F L$, $\Delta$ and $U . \Delta t$ of Tables II and III have been tested according to the initial values of Figure 3 and calculated according to the dynamic mode. The parameters $\omega(t)$ and $M_{t}(t)$ highly depend on inertia $J$ of the rotor. If $J$ weight is heavy, $\omega_{\max }$ and 
$M_{t}$ are low and vice-versa. $\omega$ and $M_{t}$ of this study are in close link with the weight of aluminum. This stopping criterion is called a periodic steady state (PSS), a state in which all the respective wind turbine rotor dynamic parameters remain stable over a given period. The time step $\Delta t$ of the study is invariable for a particular dynamic simulation, but changes according to the intensity of $M_{f}$ were applied to the wind turbine rotor at each simulation.

In this section, we have to determine the static torque coefficient $C_{m}$, the dynamic torque coefficient $C_{t}$ and the power coefficient $C_{p}$. They are the main VAWT parameters and their expressions are given by the following relations:

$$
\begin{gathered}
C_{m}=\frac{M}{\frac{1}{4} \rho D A U^{2}} \\
C_{t}=\frac{M_{t}}{\frac{1}{4} \rho D A U^{2}} \\
C_{p}=\frac{P}{\frac{1}{2} \rho A U^{3}}
\end{gathered}
$$

where $A$ is the rotor projected area, $D$ is the rotor diameter, $U$ is a free stream velocity. $M$ is the static torque, $M_{t}$ is the dynamic torque and $P$ is the aerodynamic power.

\section{Equation of motion of the Savonius rotor}

In this section, we give a numerical treatment of the rotor rotation in a fluid. By neglecting some motion of the rigidrotor, we reduced the complexity of the system to a 1-DOF problem. The rotor inertia tensor $J$ is part of the equation of motion of the rigid-rotor and its expression is given below:

$$
J=\left[\begin{array}{ccc}
J_{O x} & -J_{x y} & 0 \\
-J_{x y} & J_{O y} & 0 \\
0 & 0 & J_{O z}
\end{array}\right]
$$

where $J_{O x}, J_{O y}$ and $J_{O z}$ are the main moments of inertia of the rotor. $J_{x y}$ is the product of inertia of the rotor.

The equation of motion of the rigid-rotor is given by the following relation:

$$
J_{O z} \ddot{\theta}=M_{O z}+G_{O z}
$$


where $J_{O z}$ is the component of the rotor inertia tensor $J$ along $O z$ axis. $M_{O z}$ is the moment of forces acting on the Savonius rotor. $G_{O z}$ represents the forces acting on the rotor. Assuming that the Savonius rotor makes a perfect pivot with the rotational axis $O z$ of the rotating mesh, this implies that $G_{O z}$ is equal to zero. The reduced form of the rotation equation of the Savonius rotor is then:

$$
\begin{gathered}
J_{O z} \ddot{\theta}=M_{O z} \\
M_{O z}=\left(M_{p}+M_{\tau}+M_{f}\right) f_{r}
\end{gathered}
$$

where $M_{p}$ corresponds to the moments of pressure, $M_{\tau}$ is the moment of the viscous stresses, $M_{f}$ is the moment of external forces. $f_{r}$ is the ramping factor and it was applied to $M_{O z}$ and $G_{O z}$ on the body of the rotor. It was used to minimize the numerical shock caused by the coupling between structural and fluid dynamics at the start of the simulation $[21]$.

$$
f_{r}= \begin{cases}0 & : t=0 \\ \frac{t}{t_{r}} & : 0 \leq t \leq t_{r} \\ 1 & : t \geq t_{r}\end{cases}
$$

where $t$ is the time. $t_{r}$ is the duration of the ramp. This kind of numerical strategy reduces the instabilities at the beginning of the simulations.

The specificity of the dynamic study compared to the steady-state study takes into account the rotor inertia tensor $J$ and the rotor angular acceleration $\ddot{\theta}$ in problem formulation. Eq. (7) of the rigid-rotor is then solved at each time step $\Delta t$ [21]. The variation of the intensity of $M_{p}$ and $M_{\tau}$ at each rotor angle $\theta$ influences the oscillation of $\omega$ curve in Figure 5. $\omega$ and $\theta$ result from the integration of the rotor angular acceleration $\ddot{\theta} . \omega$ and $M_{t}$ evolve according to the computational time $T$ and the rotor angle $\theta$.

\section{Time step}

The time step $\Delta t$ varies according to the minimal cell size $\Delta$ of the computational domain, the rotor angular velocity $\omega$ and the CFL number. At each dynamic simulation, the stabilized $\omega$ was obtained in a PSS of the rigid-rotor by averaging the oscillations of $\omega(t)$. The same method was used to determine the average value $M_{t}$ of the dynamic torque $M_{t}(t)$.

10 
Here, the rotor revolution number is calculated from $45 \mathrm{~s}$. If the PSS is reached, the average value of the two dynamic quantities $\omega$ and $M_{t}$ are stable and calculated over twelve period. The more the averaging period approaches the total simulation time T, the higher the accuracy of the average values. Figure 5 shows that the rotor performed 88 revolutions before reaching the PSS calculated from a simulation time of $45 \mathrm{deg} .88$ revolutions corresponds to the numbers of peaks of $\theta$ until a simulation time of $45 \mathrm{~s}$. This number of revolutions corresponds to an asymptotic convergence of average output variables. $\Delta t$ plays an important role in a numerical simulation and it permits the determination of dynamic parameters of the rotor along the computational time $T$. A wrongly estimated $\Delta t$ can lead the rigid-rotor to a false PSS.

The CFL is related to $\Delta t, \mathrm{R}, \Delta$ and $\omega$ parameters $[23,24]$. The maximum $C F L$ value should be low for the consistency of the simulation results [21]. 5 is the maximum value of CFL number that was obtained for the dynamic simulation and implicit Euler integration. CFL and $y^{+}$are the two parameters that control the accuracy of simulation results.

\subsubsection{Vortex identification}

In dynamic simulations, the analysis of dynamic phenomenon that occurs during the Savonius rotor rotation requires a robust visualization method. Among the existing methods, Jeong and Hussain [25] have presented the $\lambda_{2}$ approach which describes the formation and destruction of the vortices through the Savonius rotor blades and endplates. The $\lambda_{2}$ method is based on two criteria : a vortex core must have a net vorticity and the geometry of the identified vortex core must be a Galilean invariant [26]. Taking the gradient of Navier-Stokes equations and decomposing them into a symmetric and an antisymmetric part, they derive the vorticity transport equation and the strain rate transport equation. The latter is represented as follows:

$$
\frac{D S_{i j}}{D t}-\nu S_{i j, k k}+\Omega_{i k} \Omega_{k j}+S_{i k, k j}=-\frac{1}{\rho} p_{i j}
$$

where $p_{i j}$ is the hessian pressure, $S$ the deformation rate tensor

$$
S_{i j}=\frac{1}{2}\left(\frac{\partial u_{i}}{\partial x_{j}}+\frac{\partial u_{j}}{\partial x_{i}}\right)
$$

and $\Omega$, the rotation rate tensor

$$
\Omega_{i j}=\frac{1}{2}\left(\frac{\partial u_{i}}{\partial x_{j}}-\frac{\partial u_{j}}{\partial x_{i}}\right)
$$


If the two eigenvalues of $p_{i j}$ are positive, this indicates the presence of a minimum local pressure and corresponds to a vortical region [26]. Discarding the contribution of the unsteady irrotational straining and viscous effects in Eq. (10) allowed us to obtain a better contribution for the existence of a vortex [27]. Jeong and Hussain [25] have pointed out that the presence of a minimum pressure is the basis of the vortex identification technique, but that it is not a sufficient detection criterion for a vortex core in general. The two terms removed from Eq. (10) are considered to be the main cause of this inaccuracy [25, 27]. Jeong and Hussain define a vortex as a connected region where $S^{2}+\Omega^{2}$ are two negative eigenvalues ( $S$ and $\Omega$ are respectively the symmetric and antisymmetric parts of the velocity gradient tensor $\nabla u$ ). The tensor $S^{2}+\Omega^{2}$ is symmetric and only admits real eigenvalues. If the eigenvalues are in the order of $\lambda_{1} \geqslant \lambda_{2} \geqslant \lambda_{3}$, the vortex identification criterion is equivalent to $\lambda_{2}<0$.

\section{RESULTS AND DISCUSSION}

In order to validate the VAWT model based on the fully coupled fluid rigid-rotor interaction, our numerical results were compared to the experimental investigations of Blackwell et al. [9]. The difficulty with the dynamic simulation comes from the important computational time $T$ and the choice of the resolution methods that must be adopted. The integration of the rotation equation of the Savonius rotor gives information about its mechanical behavior. The analysis of the airflow and the vortex generation during the dynamic simulation allowed better understanding concerning the mechanism of the Savonius rotor rotation.

\subsection{Steady-state study of the Savonius rotor}

In this section of the present article, results of the steady-state three-dimensional CFD simulation were validated with the steady-state experimental data [9]. The static torque coefficient $C_{m}$ curve was obtained at different rotor angle $\theta \cdot \theta$ evolving from 0 to $360 \mathrm{deg}$ with a rotor angular step $\Delta \theta$ of $15 \mathrm{deg}$. The optimum position for the Savonius rotor was identified at $\theta=30 \operatorname{deg}[5,8]$. The numerical $C_{m}$ curves of the present study have a minimum at $\theta=124.6 \mathrm{deg}$. Menet and Leiper [8] conducted a two-dimensional steady-state simulation with a standard $\mathrm{k}-\varepsilon$ model and compared their results with experimental data (see the Figure 4 below) [9]. The experimental $C_{m}$ curve does not last over a whole period, but it is sufficient to make a comparison of results [9]. Among these four curves, the minimum of the numerical $C_{m}$ curves of the present study are close to the experimental $C_{m}$ curve [9]. The minimums of the experimental $C_{m}$ curve and the SST k- $\omega$ model $C_{m}$ curve are (respectively) 0.05 for $\theta=124.6 \operatorname{deg}$ and 0.043 for $\theta=135 \operatorname{deg}$ [9]. The minimum of the 
three-dimensional $C_{m}$ curve with the standard k- $\varepsilon$ model is 0.038 for $\theta=120 \mathrm{deg}$. The maximums of the two-dimensional $C_{m}$ curve of Menet and Leiper [8] and the three-dimensional $C_{m}$ curve for the present study with the standard k- $\varepsilon$ model are 0.79 and 0.7979 respectively for $210 \mathrm{deg}$. The experimental $C_{m}$ curve and the SST k- $\omega$ model curve have the same maximum of 0.82 at $\theta=204.33 \mathrm{deg}$ and $210 \mathrm{deg}$ respectively [9]. For $\theta$ from $170 \mathrm{deg}$ to $253 \mathrm{deg}$, the $C_{m}$ curves of the standard $\mathrm{k}-\varepsilon$ and SST k- $\omega$ models have an acceptable evolution. For $\theta$ in range of 0 deg to 253 deg, we deduce that the experimental $C_{m}$ curve was accurately predicted by the SST k- $\omega$ model in comparison with the standard k- $\varepsilon$ model [9]. The average $C_{m}$ values obtained with the standard k- $\varepsilon$ and SST k- $\omega$ models are respectively $39.5 \%$ and $41.3 \%$.

Figure 4. Comparison of the experimental and the numerical static torque coefficient.

For this three-dimensional geometry of the rotor, the $C_{m}$ curves obtained are always positive. For any $\theta$, this result is in conformity with the Blackwell et al. [9] results. Many authors show different three-dimensional geometries of the Savonius rotor with the negative parts of the $C_{m}$ curves between $\theta$ from 134 to $165 \mathrm{deg}$. The negative regions arise from the progressive change in the contribution of each rotor blade to the torque generated by the rotor. Between these two angles, the convex surface of the retreating blade is much exposed to the wind incidence in comparison to the concave part of the advancing blade. The result of $\mathrm{Cm}$ curves between these two angles are negative. Therefore, the Cm curve takes often negative values between these $\theta$.

So, the shape, the maximums, and the minimums of the experimental $C_{m}$ curve are accurately predicted by the turbulence models that are used [9]. In Figure 4, we can observe an improvement of both three-dimensional steady-state cases compared to a two-dimensional steady-state case. It also appears that, when comparing the SST k- $\omega$ and standard $\mathrm{k}-\varepsilon$ models, a better approximation of the experimental $C_{m}$ curve is obtained with the SST k- $\omega$ model.

\subsection{Dynamic study of the Savonius rotor}

The dynamic study of the Savonius rotor gives the dynamic torque coefficient $C_{t}$ curves and power coefficient $C_{p}$ curve in Figures 6,7 and 8. These curves are obtained by the superposition of several PSS of the rotor. To define these curves, simulations were carried out in a range of moment of external forces $M_{f}$ in Tables II and III below.

Figures 7 and 8 depend on $\lambda$ of the Savonius rotor and its expression is defined as follows:

$$
\lambda=\frac{R \omega}{U}
$$


Table II. Summary of data obtained from the dynamic study of the Savonius rotor with the standard k- $\varepsilon$ model.

\begin{tabular}{lccccccc}
\hline$M_{f}(\mathrm{Nm})$ & $\lambda$ & $M_{t}(\mathrm{Nm})$ & $C_{t}$ & $\omega(\mathrm{rad} / \mathrm{s})$ & $\mathrm{P}(\mathrm{W})$ & $C_{p}$ & $\Delta t(\mathrm{~s})$ \\
\hline-4.2 & 0 & 4.20 & 0.323 & 0 & 0 & 0 & 0.02 \\
-4.0 & 0.22 & 4.56 & 0.376 & 3.40 & 15.48 & 0.082 & 0.001 \\
-3.9 & 0.42 & 4.35 & 0.359 & 6.55 & 28.48 & 0.151 & 0.001 \\
-3.6 & 0.58 & 4.37 & 0.360 & 9.01 & 39.39 & 0.209 & 0.001 \\
-3.0 & 0.81 & 3.21 & 0.265 & 12.57 & 40.34 & 0.214 & 0.001 \\
-2.6 & 0.95 & 2.60 & 0.214 & 14.67 & 36.16 & 0.202 & 0.0005 \\
-2.0 & 1.09 & 2.01 & 0.166 & 16.90 & 33.99 & 0.181 & 0.0005 \\
-0.1 & 1.47 & 0.59 & 0.049 & 22.77 & 13.44 & 0.072 & 0.0004 \\
\hline
\end{tabular}

Table III. Summary of data obtained from the dynamic study of the Savonius rotor with the SST k- $\omega$ model.

\begin{tabular}{lccccccc}
\hline$M_{f}(\mathrm{Nm})$ & $\lambda$ & $M_{t}(\mathrm{Nm})$ & $C_{t}$ & $\omega(\mathrm{rad} / \mathrm{s})$ & $\mathrm{P}(\mathrm{W})$ & $C_{p}$ & $\Delta t(\mathrm{~s})$ \\
\hline-4.2 & 0 & 4.12 & 0.340 & 0 & 0 & 0 & 0.02 \\
-4.0 & 0 & 4.12 & 0.340 & 0 & 0 & 0 & 0.001 \\
-3.95 & 0.19 & 4.44 & 0.359 & 2.83 & 12.35 & 0.065 & 0.001 \\
-3.9 & 0.57 & 4.57 & 0.370 & 8.84 & 40.41 & 0.207 & 0.001 \\
-3.6 & 0.69 & 3.70 & 0.305 & 10.71 & 39.61 & 0.210 & 0.001 \\
-3.0 & 0.85 & 2.65 & 0.256 & 13.19 & 39.56 & 0.210 & 0.001 \\
-2.6 & 0.95 & 2.65 & 0.219 & 14.75 & 39.10 & 0.208 & 0.0005 \\
-2.0 & 1.11 & 2.00 & 0.165 & 17.22 & 34.44 & 0.180 & 0.0005 \\
-0.1 & 1.54 & 0.28 & 0.023 & 23.89 & 6.69 & 0.036 & 0.0004 \\
\hline
\end{tabular}

Generally, for each dynamic simulation, the rotor angular velocity $\omega$ of the rigid-rotor starts at $0 \mathrm{rad} / \mathrm{s}$ before reaching its PSS. Each rigid-rotor PSS corresponds to a specific $\omega$. The time step $\Delta t$ was fixed by the dynamic torque coefficient of experimental data. The number of iterations at each $\Delta t$ was set to 20 and the sub-iteration number for the 1-DOF solver must be higher than 10 to attest the convergence of the residuals. The convergence criteria imposed for all residual parameters of continuity, momentum, turbulent kinetic energy (Tke) and turbulent dissipation rate (Tdr) were fixed at $10^{-6}$. Higher values of this criterion produce invalid results. The $\Delta t$ is a parameter which intervenes in the modeling of the rigid-rotor motion. The choice of $\Delta t$ is based on the compromise between accuracy and the computational time $T$. A higher $\Delta t$ may compromise the validity of results and a low $\Delta t$ increases computing resources. The $\omega$ of the rigid-rotor during the transitory state and in a PSS was imposed by the Eq. (7). The $\omega$ and the dynamic torque $M_{t}$ curves of the rigid-rotor are shown in Figure 5. These curves correspond to the moment of external forces $M_{f}=-2.6 \mathrm{Nm}$. At $T=0 \mathrm{~s}$, the rigid-rotor is positioned at the rotor angle $\theta=0 \mathrm{deg}$ and, after this time, it starts moving. As $T$ increases, the $\omega$ and $M_{t}$ parameters tend to a stable average value in their PSS.

Figure 5. Time-dependent dynamic torque, rotor angular velocity and rotor angular positions.

The increase of the rotor angular velocity $\omega$ in Figure 5 corresponds to the decrease of its dynamic torque $M_{t}$. These two parameters oscillate around an average value of $14.67 \mathrm{rad} / \mathrm{s}$ and $2.6 \mathrm{Nm}$ in their PSS. Figure 5 also shows that the SST 
k- $\omega$ model has a rapid convergence compared to the standard k- $\varepsilon$ model. The $\omega$ and the dynamic torque $M_{t}$ curves of the SST k- $\omega$ model are consistent with those obtained by the standard $\mathrm{k}-\varepsilon$ model. These results are consistent with the data given in Blackwell et al. [9] and this confirms the robustness of the SST k- $\omega$ model.

Some of the results obtained by D'Alessandro et al. [14] on the dynamic torque $M_{t}$ have also been underlined in this study (see Figure 6). The present results show that the dynamic torque curves can have negative values depending on the rotor angle $\theta$. This is explained by the fact that, in Figure 5, the results have a negative part from a time of $30 \mathrm{~s}$ until the end of the computational time $T$. The negative values of the dynamic torque coefficient $C_{t}$ curves of a Savonius rotor in polar coordinates is subjected to a moment of external forces $M_{f}$ near $0 \mathrm{Nm}$.

Figures 6(a) and 6(b) show that the evolutions of the dynamic torque coefficient $C_{t}$ curves in polar coordinates. The moments of external forces $M_{f}$ of these curves are in the range of $-0.1 \mathrm{Nm}$ to $-4.2 \mathrm{Nm}$ for the standard k- $\varepsilon$ and SST k- $\omega$ models. The rigid-rotor behaviors reported by these two curves show similarities, except for the case where it was loaded by $M_{f}=-0.1 \mathrm{Nm}$. The rigid-rotor starts off with the standard k- $\varepsilon$ model and $M_{f}=-4.2$ Nm. The rigid-rotor also starts off with the SST k- $\omega$ model and the two $M_{f}$ values of $-4 \mathrm{Nm}$ and $-4.2 \mathrm{Nm}$. The first full rotation of the rigid-rotor in Figure 6(a) with $M_{f}=-4 \mathrm{Nm}$ and a time step $\Delta t=0.001 \mathrm{~s}$ was obtained with the standard k- $\varepsilon$ model. The first full rotation of the rigid-rotor where it is subject to $M_{f}=-3.95 \mathrm{Nm}$ and a $\Delta t=0.001 \mathrm{~s}$ in Figure 6 (b) was obtained with the SST k- $\omega$ model. These observations correspond to the high maximum values of $C_{t}=0.64$ obtained with the standard k- $\varepsilon$ model and $C_{t}=0.61$ obtained with the SST k- $\omega$ model. Using the standard k- $\varepsilon$ model and $M_{f}=-4.2$ Nm, the rigid-rotor oscillates between the rotor angles $\theta$ of $73.48 \mathrm{deg}$ and $77.75 \mathrm{deg}$ and tends to infinity in $\theta=75.44 \mathrm{deg}$. With the SST k- $\omega$ model and $M_{f}=-4 \mathrm{Nm}$, the rigid-rotor oscillates between $\theta=10.10 \mathrm{deg}$ and $90 \mathrm{deg}$ and tends to infinity in $\theta=41.27 \mathrm{deg}$. The $C_{t}$ curve obtained with the SST k- $\omega$ model and $M_{f}=-4.2 \mathrm{Nm}$ shows that the rigid-rotor oscillates between $\theta=29.05$ deg and $90 \mathrm{deg}$ and tends to infinity in $\theta=47.55 \mathrm{deg}$. With $M_{f}$ of $-0.1 \mathrm{Nm},-2 \mathrm{Nm}$ and $-2.6 \mathrm{Nm}$, the $C_{t}$ curves obtained by the standard $\mathrm{k}-\varepsilon$ and SST k- $\omega$ models present positive and negative values.

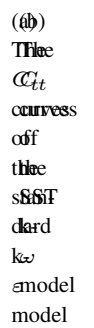

Figure 6. Dynamic torque coefficients of the Savonius rotor in polar coordinates. 
Figure 7 describes the rotor behavior in a range of moments of external forces $M_{f}$ between -4.2 to $-0.1 \mathrm{Nm}$ depending on the tip speed ratio $\lambda$. Between $M_{f}$ of $-4 \mathrm{Nm}$ to $-3.9 \mathrm{Nm}$, the $C_{t}$ curve of the standard k- $\varepsilon$ model is in harmony with the experimental $C_{t}$ curve with a small perturbation on the point corresponding to $M_{f}=-3.9 \mathrm{Nm}[9]$. From $\lambda=1.2$ to the end, the $C_{t}$ curve of the standard k- $\varepsilon$ model underestimates the experimental $C_{t}$ curve [9]. In this range of $\lambda$, the dynamic torque coefficient $C_{t}$ curve exceeds the margin of error. If we analyze the data in Tables II and III, it is found that the SST $\mathrm{k}-\omega$ model predicts the rotor behavior more accurately than the standard $\mathrm{k}-\varepsilon$ model. With the same conditions as the SST $\mathrm{k}-\omega$ model (moment of external forces $M_{f}=-0.1 \mathrm{Nm}$ and the time step $\Delta t=0.0004 \mathrm{~s}$ ), the $C_{t}$ curve of the standard k- $\varepsilon$ model is unable to reach an angular rotor velocity $\omega$ higher than $22.77 \mathrm{rad} / \mathrm{s}$. Tables II and III show that a high $\omega$ of 23.89 $\mathrm{rad} / \mathrm{s}$ was obtained with the SST k- $\omega$ model.

Figure 7. Tip speed ratio depending on the dynamic torque coefficient.

The power coefficient $C_{p}$ is an important parameter in a wind turbine study and it contributes to the wind turbine rotor design. A Savonius rotor is often designed for a tip speed ratio $\lambda$ near 1 [5]. The optimum $\lambda$ obtained by the present study is around 0.86 . The $C_{p}$ curves of the standard $\mathrm{k}-\varepsilon$ model, the SST k- $\omega$ model, and the experimental data are close and have a common maximum of 0.21 [9]. From $\lambda=0$ to 1 , the $C_{p}$ curves of the standard k- $\varepsilon$ and the SST k- $\omega$ models slightly overestimate the experimental $C_{p}$ curve, but they remain in the uncertain intervals except for $\lambda=0.21$ [9]. From $\lambda=1$ to 1.47 , the $C_{p}$ curve obtained by the standard k- $\varepsilon$ model curve underestimates the experimental $C_{p}$ curve, but it remains in the uncertain intervals [9]. The same behavior is observed for the SST k- $\omega$ model. At $\lambda$ maximum of 1.54, the power coefficient $C_{p}$ and the dynamic torque coefficient $C_{t}$ curves obtained with this model tolerably overestimate the margins of error, but they remain interesting compared to those obtained with the standard k- $\varepsilon$ model. Figures 7 and 8 show that the $C_{t}$ and $C_{p}$ curves obtained are in agreement with the experimental results.

Figure 8. Tip speed ratio depending on the power coefficient.

\subsection{Analysis of the flow field}

In the operation, the Savonius rotor generates a complex flow. Chauvin et al. [28] argued that, in their experiments in a water channel with this rotor, the retreating blade generates a turbulent wake and the advancing blade is the source of an intense trailing edge vortex rotating in the same direction as the rotor [29]. They also specify that the motive vortices occur twice per revolution [28]. Analyzing the physics of flow in the Savonius rotor revolution, it was deduced that the 
recommendations of Chauvin et al. [28] are consistent with the numerical simulation of the vortex formation in and around the rotor. For this observation, the fluid flow study in this paper is restricted to a half-turn of the rotor. Figure 9(a) shows the velocity field around a Savonius rotor taken at a rotor angle $\theta=90$ deg with a stagnation point on the extrados of the retreating blade. The $\lambda_{2}<0$ criterion of Jeong and Hussain [25] is the vortex analysis and the visualization method used here and, at this position, the emptying of the advancing blade vortices begins. This phenomenon can be seen in Figure 9(c) in which the fluids expelled from the intrados of the advancing blade create a low pressure area at the trailing edge of the blade as shown in Figures 9(b) and 9(e). This phenomenon has already been studied by Aouachria [30] and he states that it is a result of the pressure drop between the intrados and extrados at the blade tip. The importance of this fact can be shown in Figure 9(f) by expanding the diameter of the vorticity field (low pressure zone) at the trailing edge of the advancing blade. After $\theta=180 \mathrm{deg}$, the functionalities of the Savonius rotor blades were reversed. The advancing blade becomes the retreating blade and the retreating blade becomes the advancing blade. This inversion of the Savonius rotor blades functionality is confirmed by the increase of $v^{\prime}$ from $\theta=106 \operatorname{deg}$ to 206 deg and the decrease of $v^{\prime}$ from $\theta=206$ deg to $265 \mathrm{deg}$ in Table IV. We can also see in this table that the $v^{\prime}=0.33$ of $\theta=106$ deg is close to the $v^{\prime}=0.36$ of $\theta=265$ deg. According to Figure 9, the motive vortex period specified by Chauvin et al. [28] is in this range of $\theta=0$ deg to 180 deg and $180 \mathrm{deg}$ to $360 \mathrm{deg}$.

Table IV. Rotor angle depending on the dimensionless axial velocity.

\begin{tabular}{l|cccccc}
\hline$\theta(\mathrm{deg})$ & $106 \mathrm{deg}$ & $139 \mathrm{deg}$ & $173 \mathrm{deg}$ & $206 \mathrm{deg}$ & $235 \mathrm{deg}$ & $265 \mathrm{deg}$ \\
\hline$v^{\prime}$ & 0.33 & 0.43 & 0.66 & 0.76 & 0.56 & 0.36 \\
\hline
\end{tabular}

$($ (b)

Figure 9. Visualization of the velocity, pressure and vorticity fields on a symmetry plane of the Savonius rotor. The rotor angle were taken at $\theta$ of $90 \mathrm{deg}$ and $123 \mathrm{deg}$. The method of Jeong and Hussain $\left(\lambda_{2}<0\right)$ was used for the visualization of vorticity fields.

From the analysis of the vortex generated by the Savonius rotor rotation, we suggest that the swirling zone in and around the rotor partly comes in part from the low pressure formed by the vacuum created by the shear stress during its rotation. Figure 10 accurately gives the emptying phenomenon in Figures 9(c) and 9(f). Figure 10 also shows vorticity fields through the Savonius rotor filtered with $\lambda_{2}=-8000,-600$, and 0 . The restriction of $\lambda_{2}$ enabled us to obtain a better visualization of the swirling zone generated by the rotor in three dimensions. In this figure, the $\lambda_{2}=-8000$ and 0 show the extreme distribution of the vorticity fields. The $\lambda_{2}=-600$ shows a better visualization of the swirling flow induced by the rotor 
rotation. Due to the axial symmetry of the Savonius rotor, the vortices generated at the upper part and lower part of the rotor are identical.

Figure 10. Visualization of vorticity fields in and around the Savonius rotor in three-dimensions using Jeong and Hussain's technique $\left(\lambda_{2}=-8000,-600\right.$, and 0$)$.

\section{CONCLUSIONS}

A three-dimensional CFD model of a Savonius rotor has been developed in this study. The model has been validated in steady-state and dynamic conditions in comparison with experimental results. The numerical models employed are based on the Reynolds averaged Navier Stokes equations with standard k- $\varepsilon$ and SST k- $\omega$ models. The results of the steadystate and dynamic simulations of the Savonius rotor show that the best approximation of the static torque coefficient, the dynamic torque coefficient and the power coefficient are obtained with the SST k- $\omega$ model rather than with the standard $\mathrm{k}-\varepsilon$ model. The dynamic study of the Savonius rotor allowed the modeling of the dynamic torque coefficient with the application of the moment of external forces $M_{f}$ on the rigid-rotor. This study reveals that, at start-up, the dynamic torque coefficient curves of the Savonius rotor $C_{t}$ oscillate around fixed values in polar coordinates. In a PSS, the $C_{t}$ curves of the Savonius rotor that are subjected to the moment of external forces $M_{f}$ lower than $-2.6 \mathrm{Nm}$ have strictly positive values. The $C_{t}$ curves subjected to $M_{f}$ higher than $-3 \mathrm{Nm}$ have positive and negative parts. The dynamic study permitted the study of the fluid flow in and around the Savonius rotor by application of the Jeong and Hussain technique. Links between velocity, pressure, and vorticity fields have been identified. The analysis of the airflow through the Savonius rotor shows that half-period of the formation and dissipation of the vortex generated by the Savonius rotor blades rotation is in the range of the rotor angle $\theta=0 \mathrm{deg}$ to $180 \mathrm{deg}$. Due to the axial symmetry of the Savonius rotor, coherent structures have been observed at the upper and lower parts of the rotor.

The validation results show that both models that were used have difficulties in predicting the high rotor angular velocity. The present work is the preliminary study of a single VAWT simulated with a variable rotational speed $\omega$; in the future we will focus on the CFD coupling of the VAWT rotor model with buildings. This study allowed us to improve the efficiency of the VAWT, which is strongly influenced by the building shape.

18 
2

\section{REFERENCES}

1. Savonius S. J. The S-rotor and its applications. Mech. Eng. 1931; 53(5): 333-338.

2. Chauvin A., Benghrib D. Drag and lift coefficients evolution of a Savonius rotor. Experiments in Fluids 1989; 8(1-2): 118-120.

3. Modi V.J., Fernando M. S. U. K. The Savonius-rotor and its applications. Journal of Solar Energy Engineering 1931; 111: 71-81.

4. Kamoji M. A., Kedare S. B., Prabhu S. V. Performance test on helical Savonius rotor. Renewable Energy 2009; 34(3): 521-529.

5. Le Gourières D. Energie éolienne, théorie, conception et calcul pratique des installations. Eyrolles, Paris, France, 1982.

6. Ushiyama I., H., Nagai. Optimum design configurations and performances of Savonius rotors. Wind Eng. 1988; 12(1): $59-75$.

7. Menet J. L., Bourabaa N. Increase in the Savonius rotors efficiency via a parametric investigation. European Wind Energy Conference, London, 2004.

8. Menet J. L., Leiper A. Prévision des performances aérodynamiques d'un nouveau type d'éolienne à axe vertical dérivée du rotor Savonius. Actes du 17è Congrès Français de Mécanique, 2005.

9. Blackwell Ben F., Sheldahl Robert E., Feltz Louis V. Wind Tunnel Performance Data for TWO-and Three-Bucket Savonius Rotors. SAN D76-0131, 1977.

10. Gupta R., Biswas A., Sharma K. K. Comparative study of a three-bucket Savonius rotor with a combined three-bucket Savonius three-bladed Darrieus rotor. Renewable Energy 2008; 33(9): 1974-1981.

11. Menet J. L. A double-step Savonius rotor for local production of electricity: a design study. Renewable Energy 2004; 29(11): 1843-1862.

12. Fujisawa N. Velocity measurements and numerical calculations of flow fields in and around Savonius rotors. Journal of Wind Engineering and Industrial Aerodynamics 1996; 59(1): 39-50.

13. Mohamed M.H., Janiga G., Pap E., Thévenin D. Optimization of Savonius turbines using an obstacle shielding the returning blade. Renewable Energy 2010; 35(11): 2618-2626.

14. D’Alessandro V., Montelpare S., Ricci R., Secchiaroli A. Unsteady Aerodynamics of a Savonius wind rotor: a new computational approach for the simulation of energy performance. Energy 2010; 35(8): 3349-3363. 
15. Menet J. L., Cottier F. Etude paramétrique du comportement aérodynamique d'une éolienne à axe vertical de type Savonius. Actes du 16è Congrès Français de Mécanique, 2003.

16. Launder B. E., Spalding D. B. The numerical computation of turbulent flow. Computer Methods in Applied Mechanics and Engineering 1974; 3(2): 269-289.

17. Menter F. R. Two-equation eddy-viscosity turbulence models for engineering applications. AIAA J. 1994; 32(8): 15981605.

18. Yorke C. P., Coleman G. N. Assessment of common turbulence models for an idealized adverse pressure gradient flow. European journal of mechanics 2004; 23(2): 319-337.

19. Christopher L. R., Susan X. Y. Prediction of high lift: review of present CFD capability. Progress in Aerospace Sciences 2002; 38(2): 145-180.

20. Wilcox D. C. Re-assessment of the scale-determining equation for advanced turbulence models. AIAA Journal 1988; 26(11): 1299-1310.

21. CD-adapco. USER GUIDE : STAR-CCM+. Version 4.04.011, 2009.

22. McTavish S., Feszty D., Sankar T. Steady and rotating computational fluid dynamics simulations of a novel vertical axis wind turbine for small-scale power generation. Renewable Energy 2012; 41: 171-179.

23. Lui Y., Moser A., Gubler D. Influence of time step length and sub-iteration number on the convergence behavior and numerical accuracy for transient CFD. Proceedings of CFD2003,Canada; 2: 480-485.

24. Ahuja V. Optimization of fuel-air mixing for a scramjet combustor geometry using CFD and geneticalgorithm. $\mathrm{PhD}$ thesis, the Graduate Faculty of Auburn University, 2008.

25. Jeong J., Hussain F. On the Identification of a Vortex. J. Fluid Mechanics 1995; 285: 69-94.

26. Escudié R., Bouyer D., Liné A. Characterization of trailing vortices generated by a Rushton turbine. AIChE Journal 2004; 50(1): 75-86.

27. Kolár V. Vortex identification: New requirements and limitations. International Journal of Heat and Fluid Flow 2007; 28(4): 638-652.

28. Chauvin A., Botrini M., Beguier C., Brun R. Évolution du coefficient de puissance d'un rotor Savonius. C. R. Acad. Sci. Paris 296 1983; 296: 823-825.

29. Béguier C., Bousgarbiès J. L., Leweke T. Tourbillon, instabilité et décollement, Toulouse: Cépaduès, France, 2001.

30. Aouachria Z. Eolienne Savonius comportement mécanique et aérodynamique. $\mathrm{PhD}$ thesis, Université de provence, 1987. 

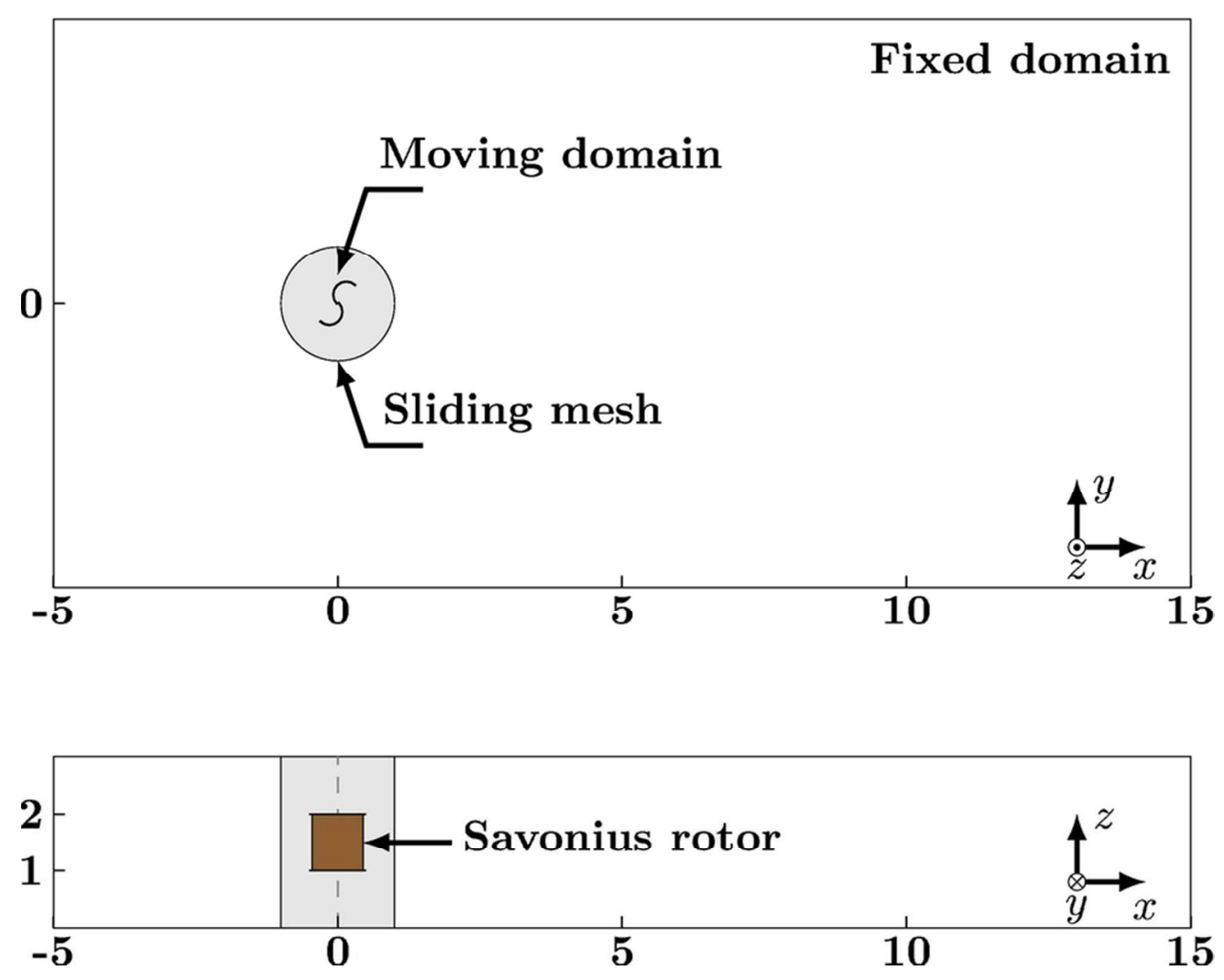

Figure1

$83 \times 66 \mathrm{~mm}(300 \times 300$ DPI $)$ 


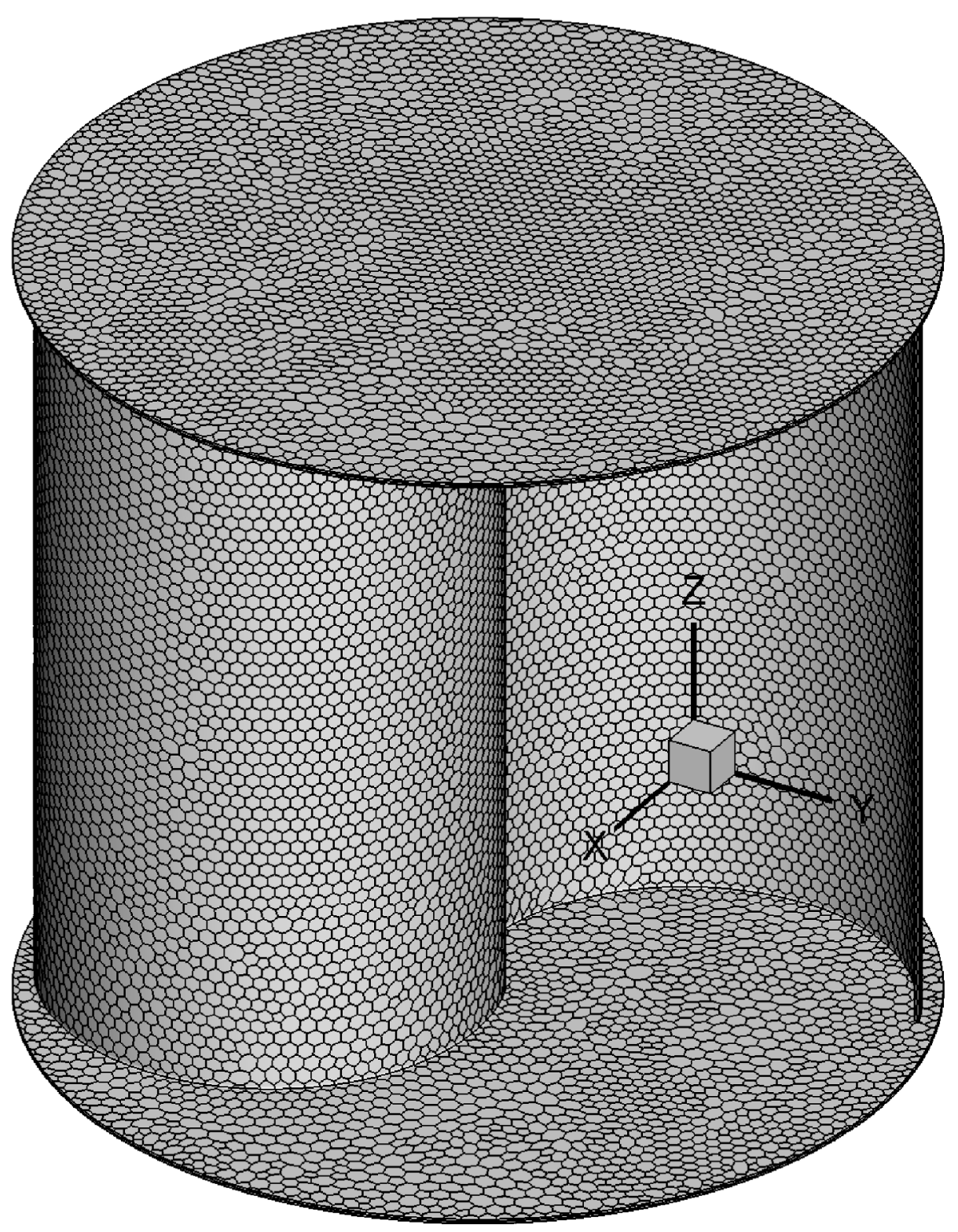

Figure2a

$371 \times 479 \mathrm{~mm}(600 \times 600$ DPI $)$ 


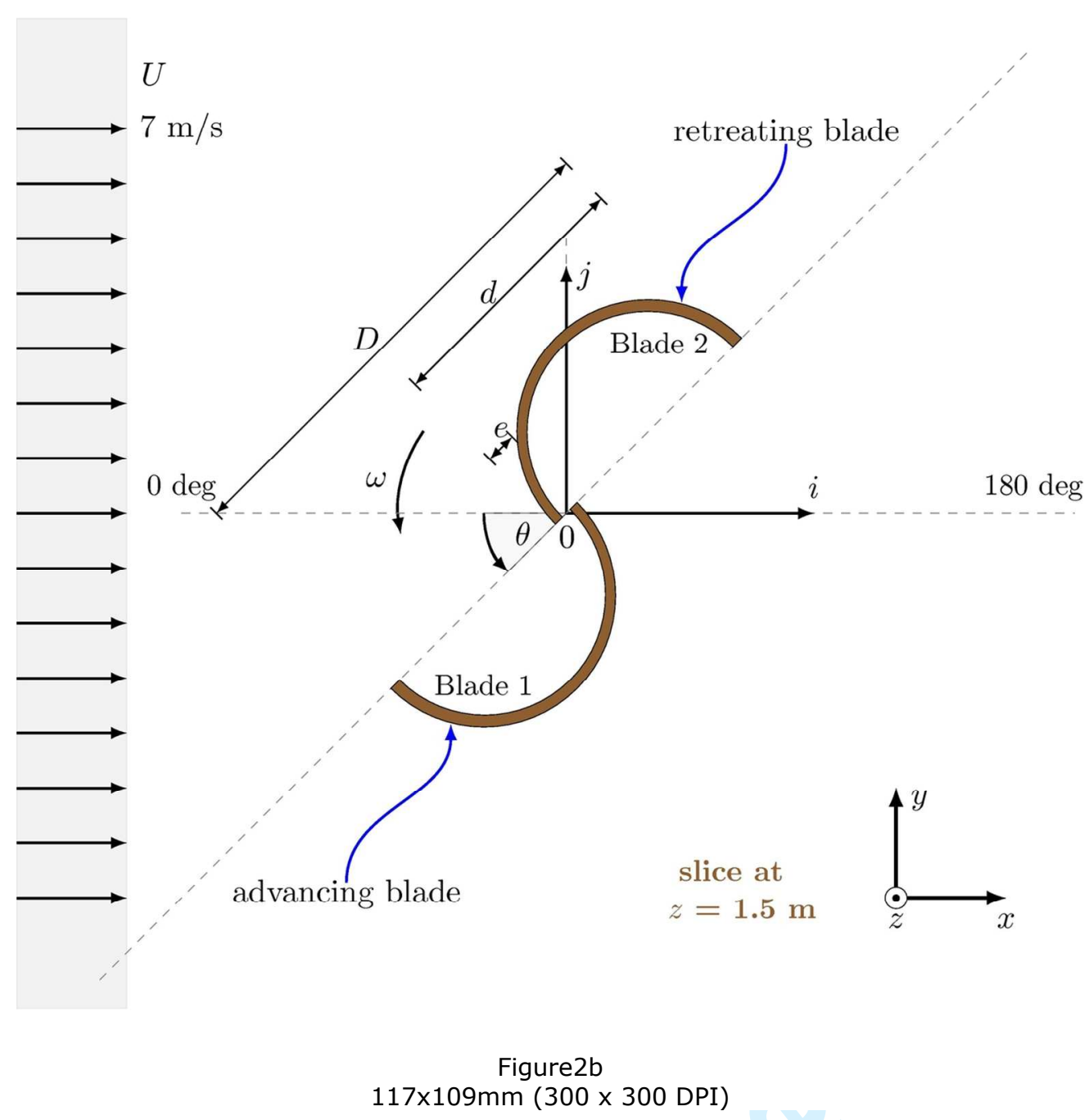




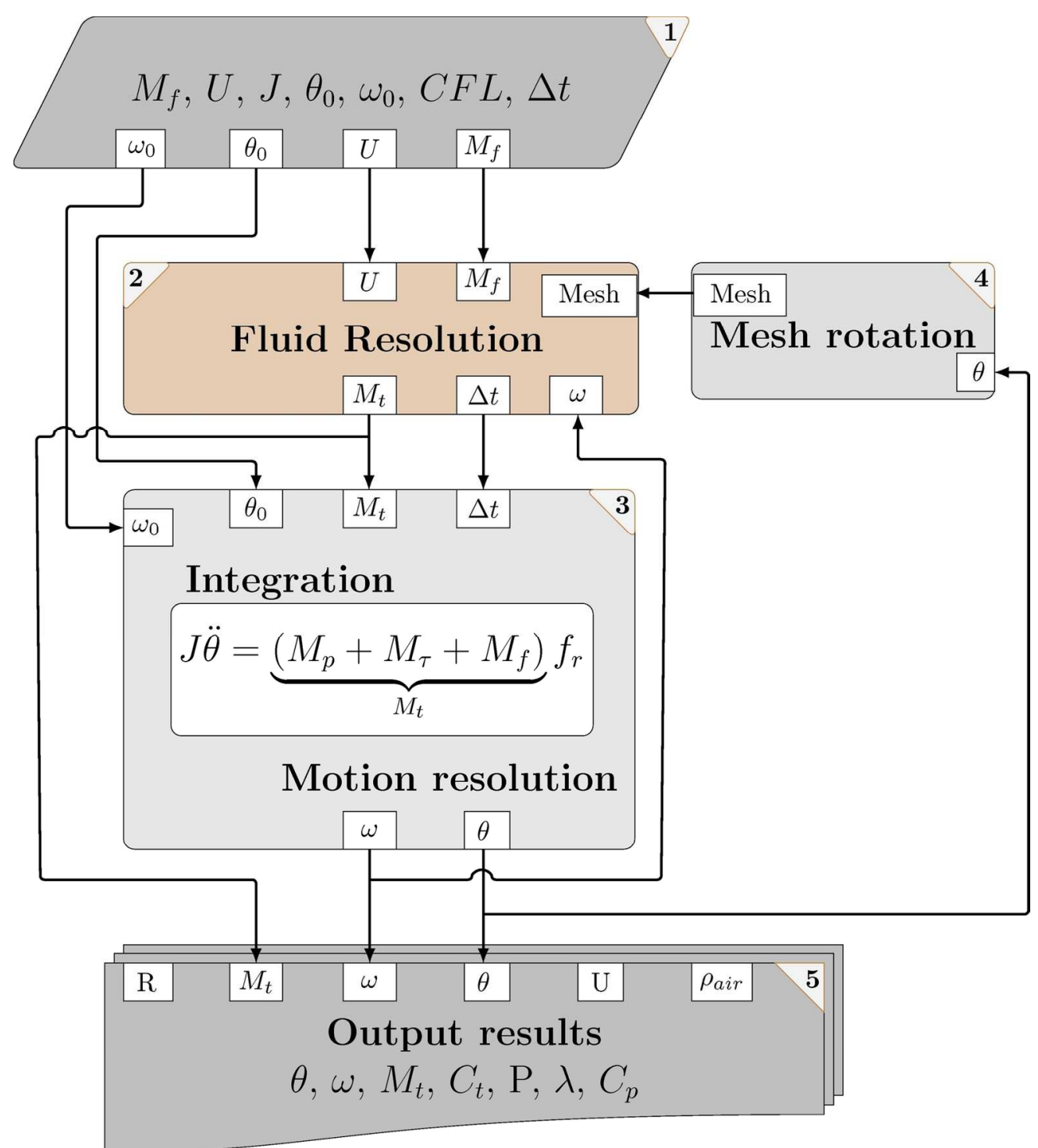

Figure3

$150 \times 167 \mathrm{~mm}(300 \times 300$ DPI $)$ 


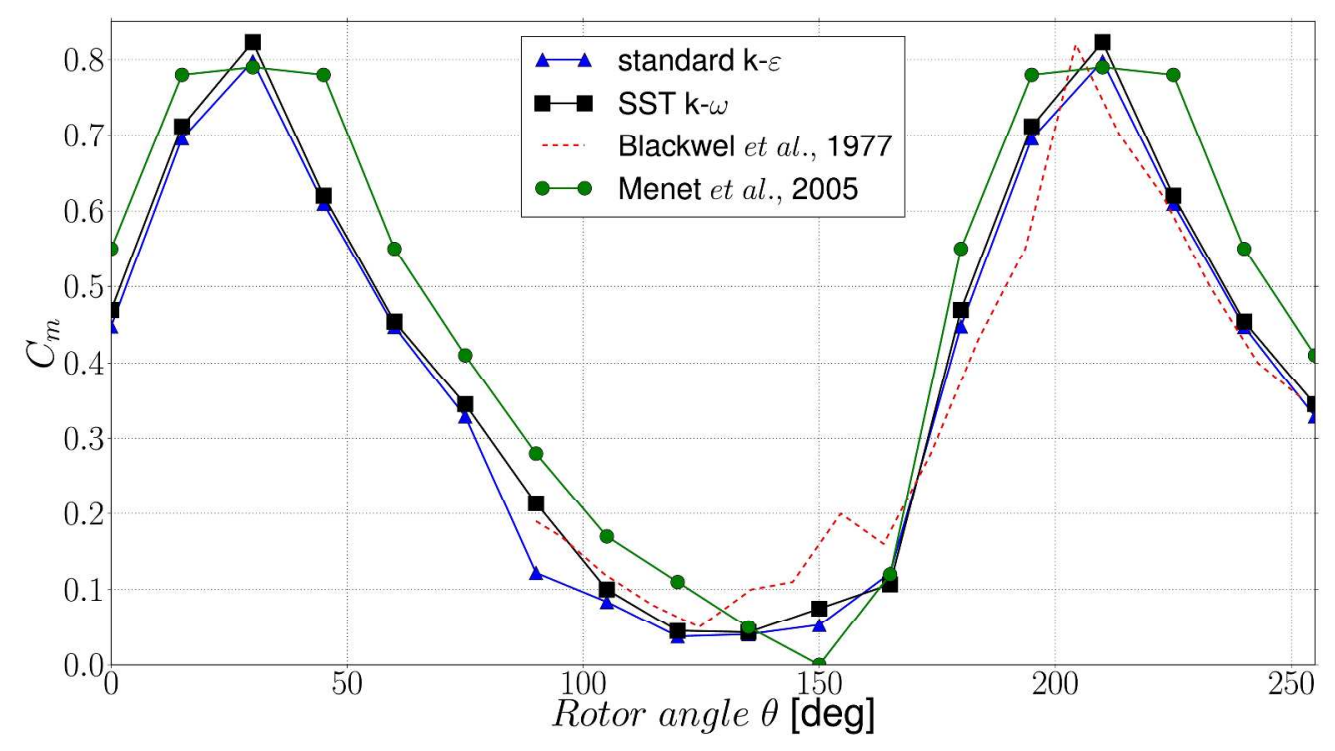

Figure4

$298 \times 166 \mathrm{~mm}(300 \times 300 \mathrm{DPI})$ 


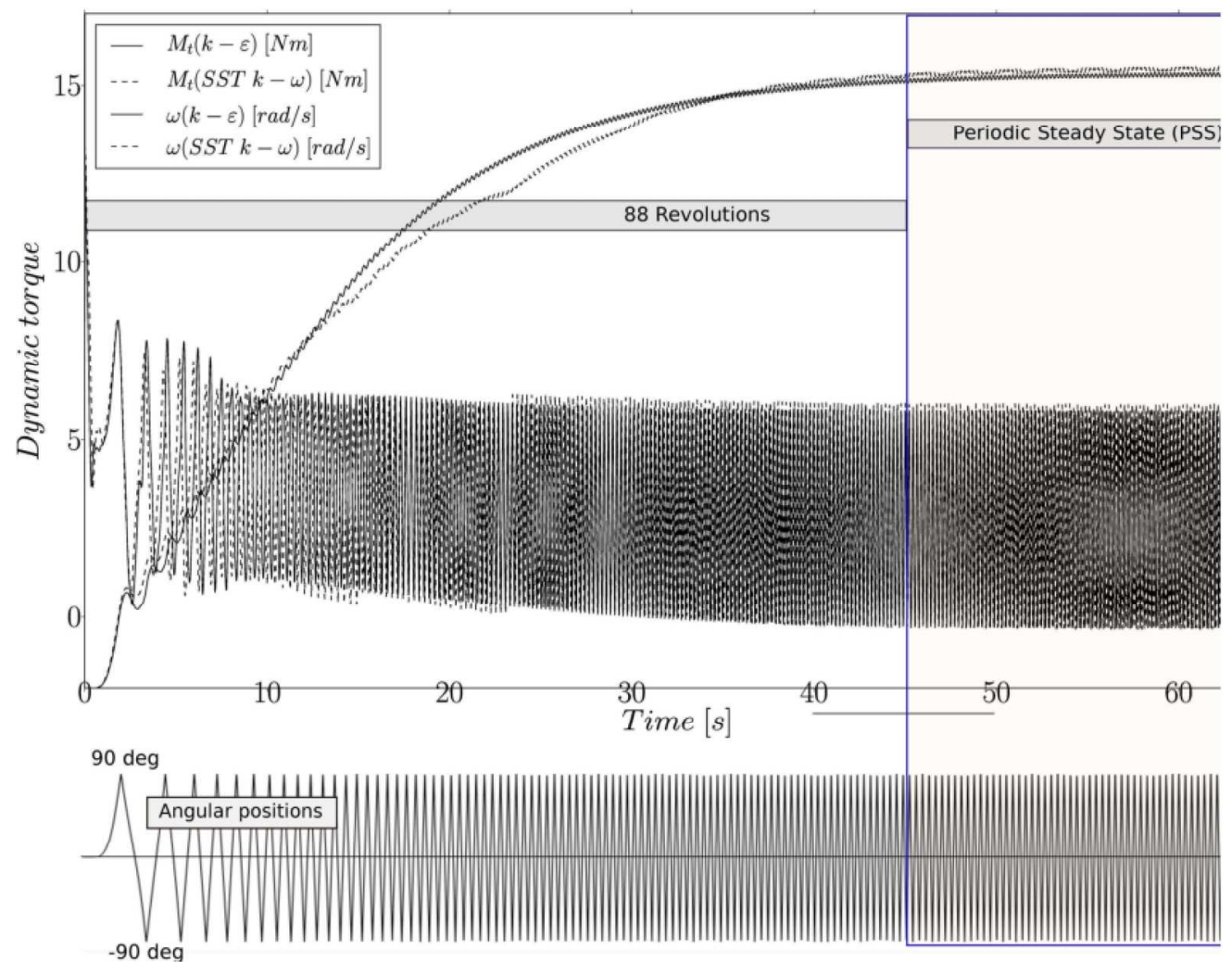

Figure5

$171 \times 135 \mathrm{~mm}(300 \times 300$ DPI $)$ 


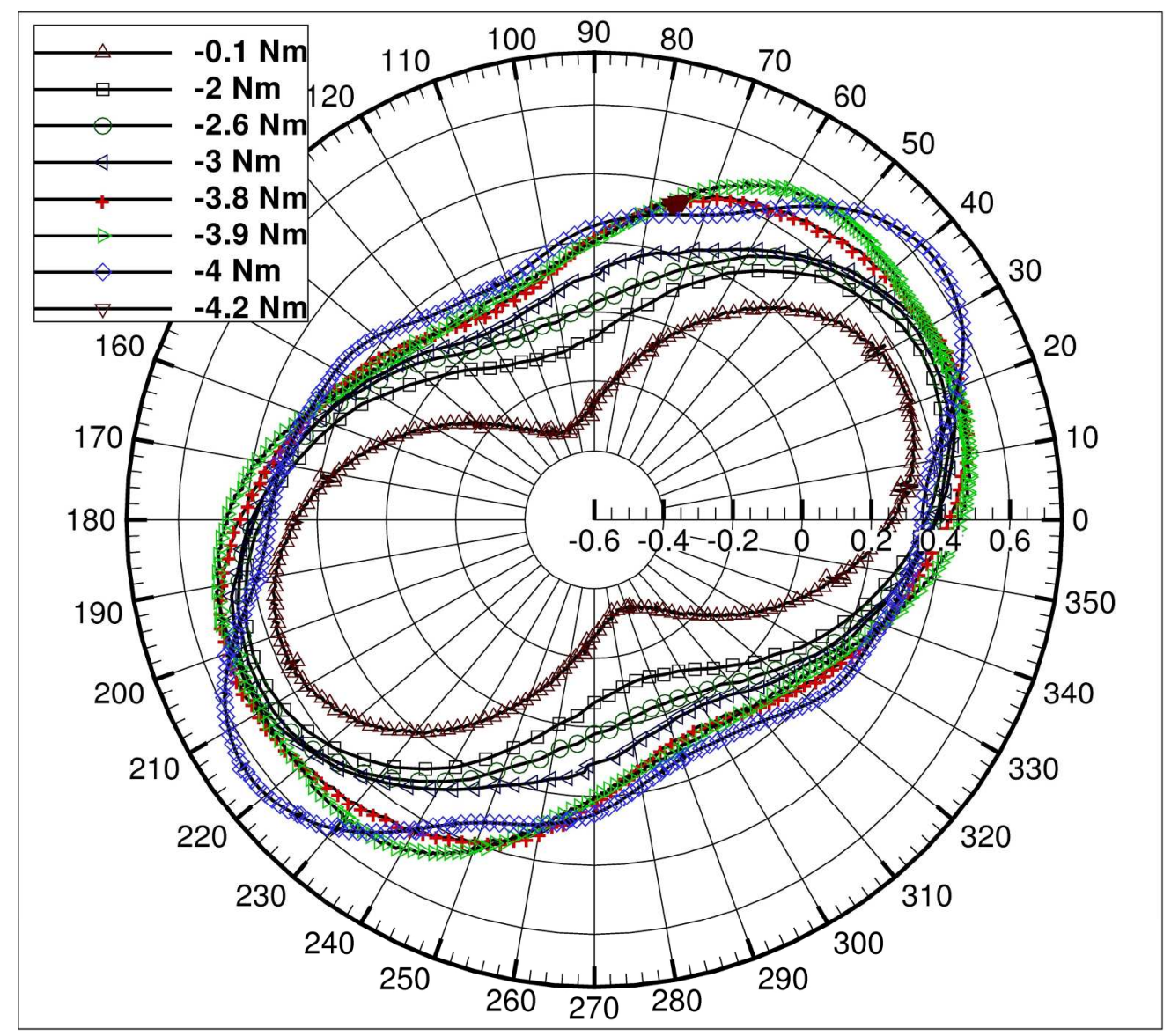

Figure6a

$203 \times 181 \mathrm{~mm}(300 \times 300$ DPI) 


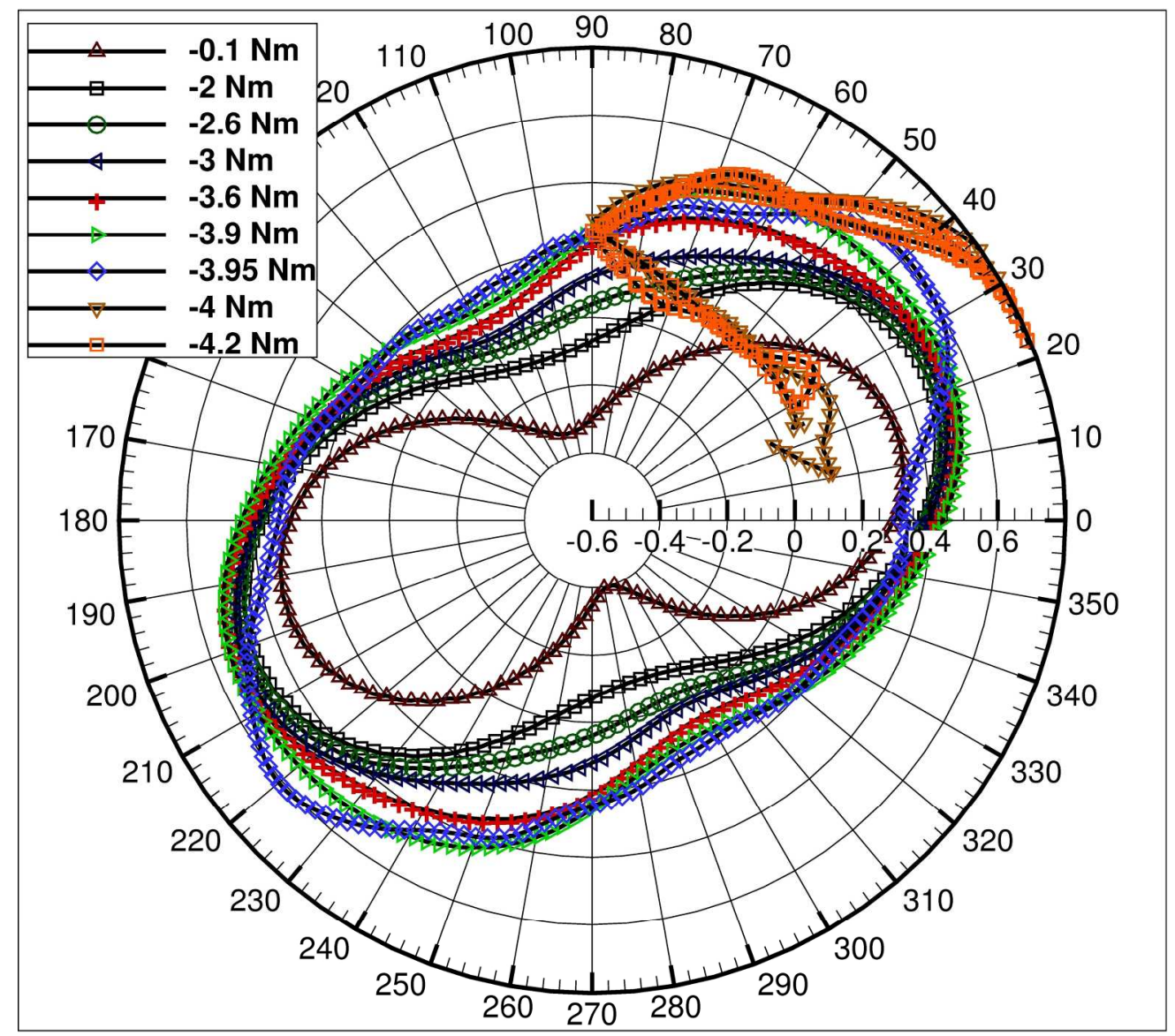

Figure $6 \mathrm{~b}$

$203 \times 181 \mathrm{~mm}(300 \times 300$ DPI) 


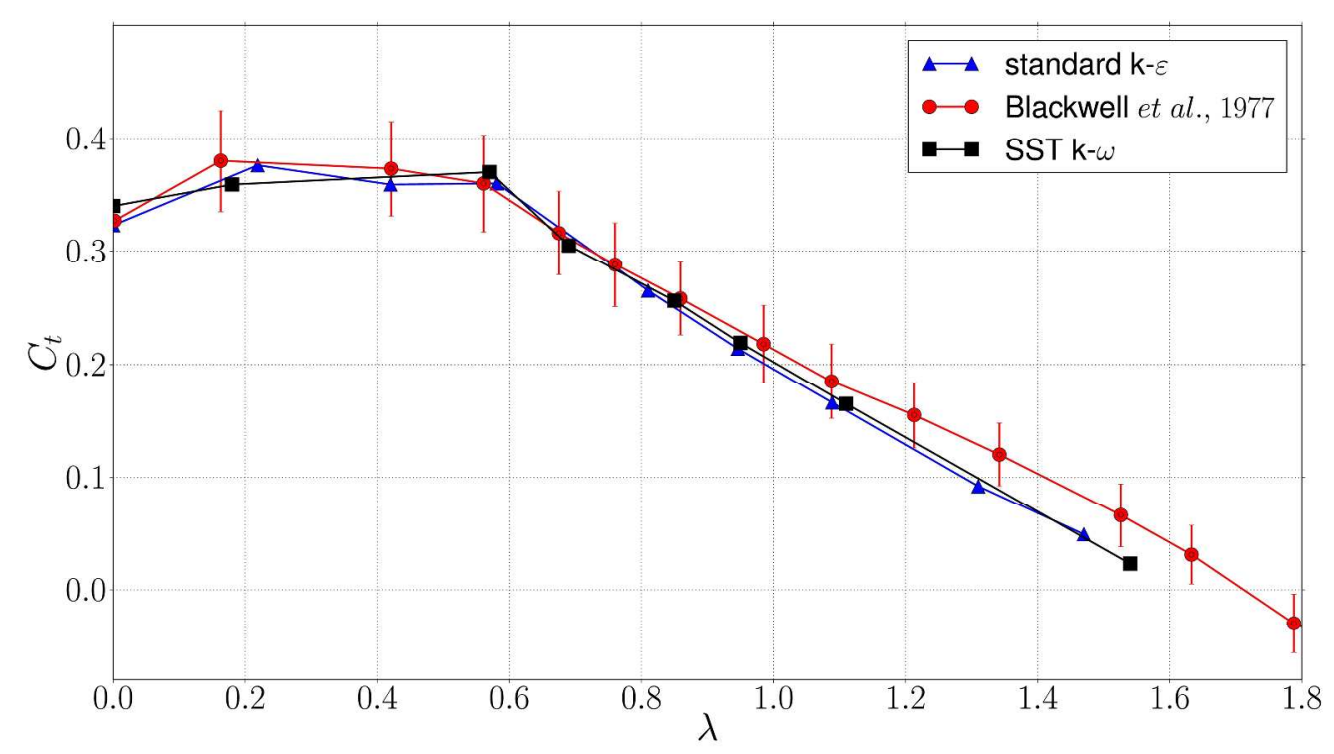

Figure7

$298 \times 166 \mathrm{~mm}(300 \times 300$ DPI) 


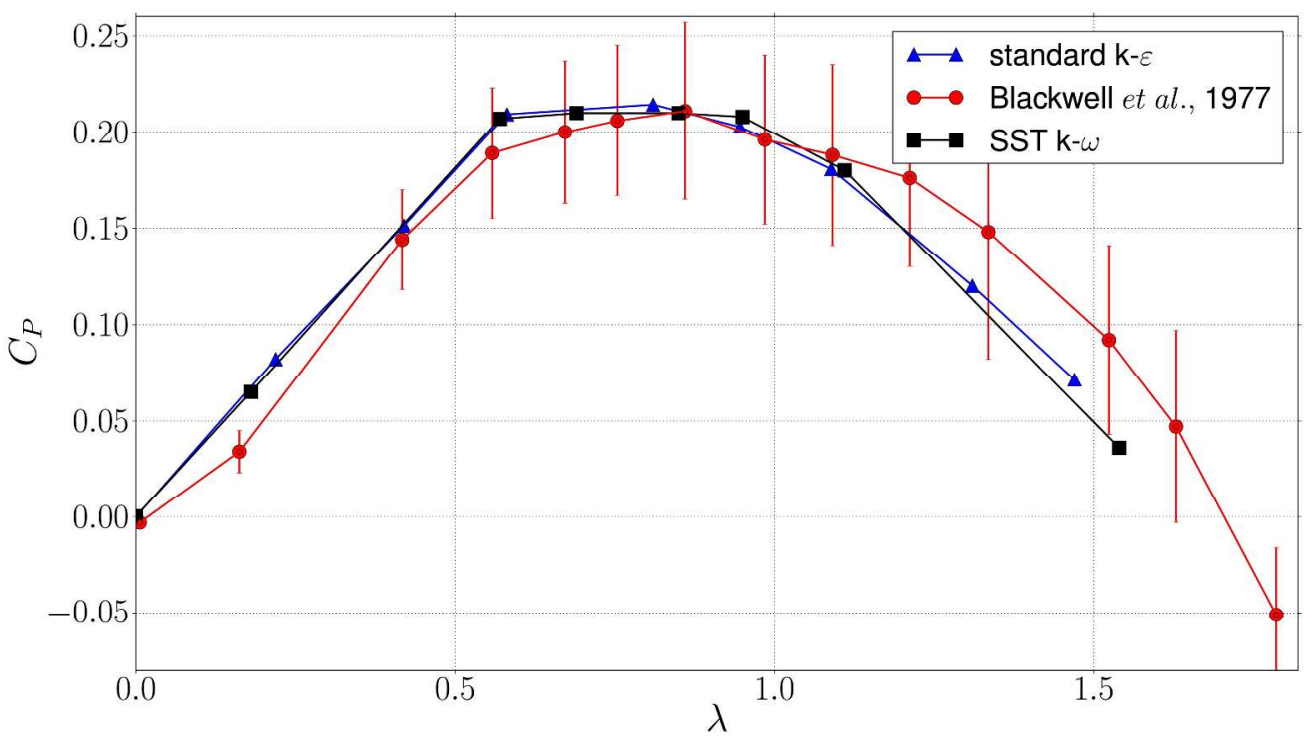

Figure8

$298 \times 166 \mathrm{~mm}(300 \times 300$ DPI $)$ 


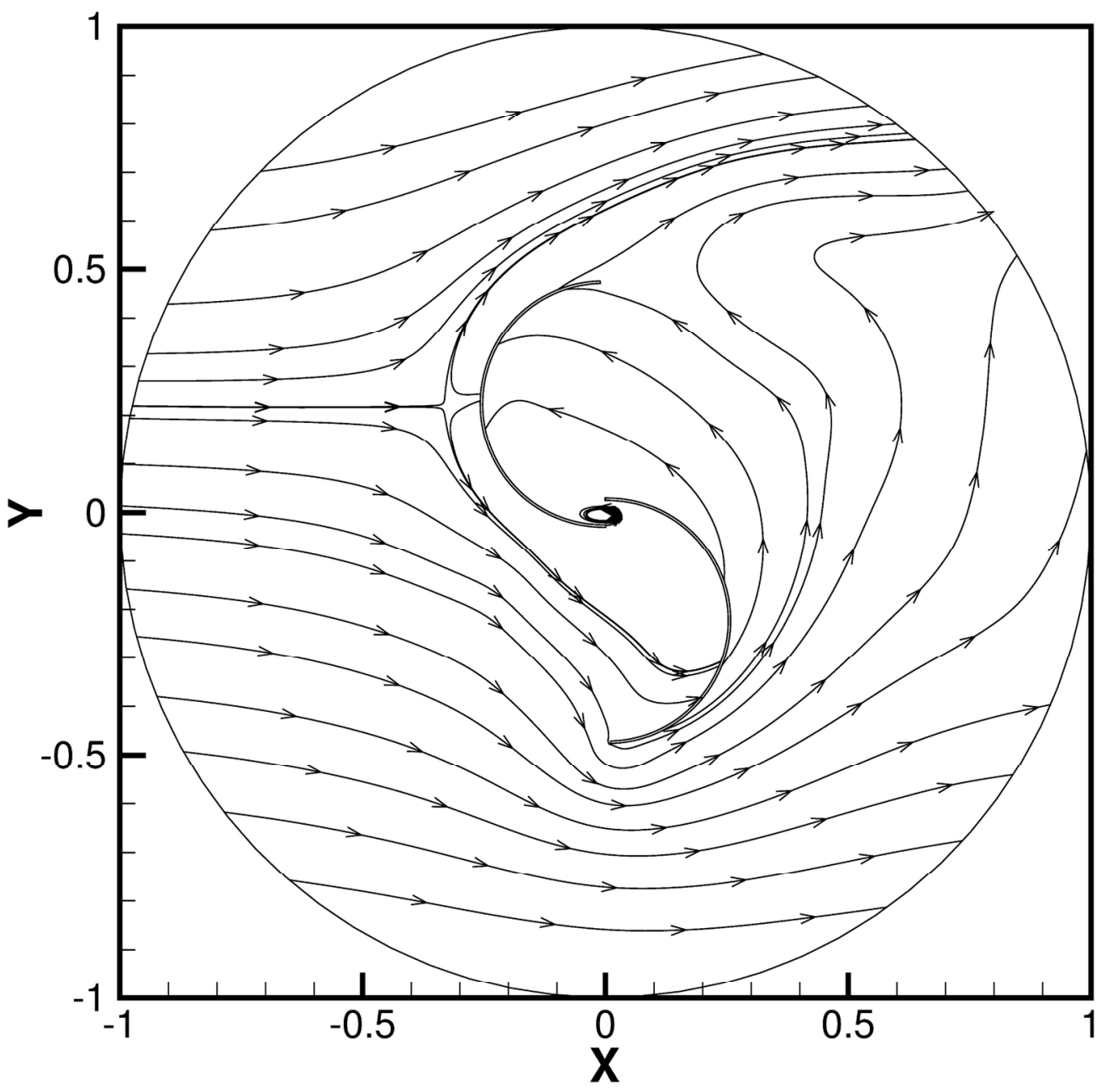

Figure9a

$169 \times 166 \mathrm{~mm}$ (300 x 300 DPI) 


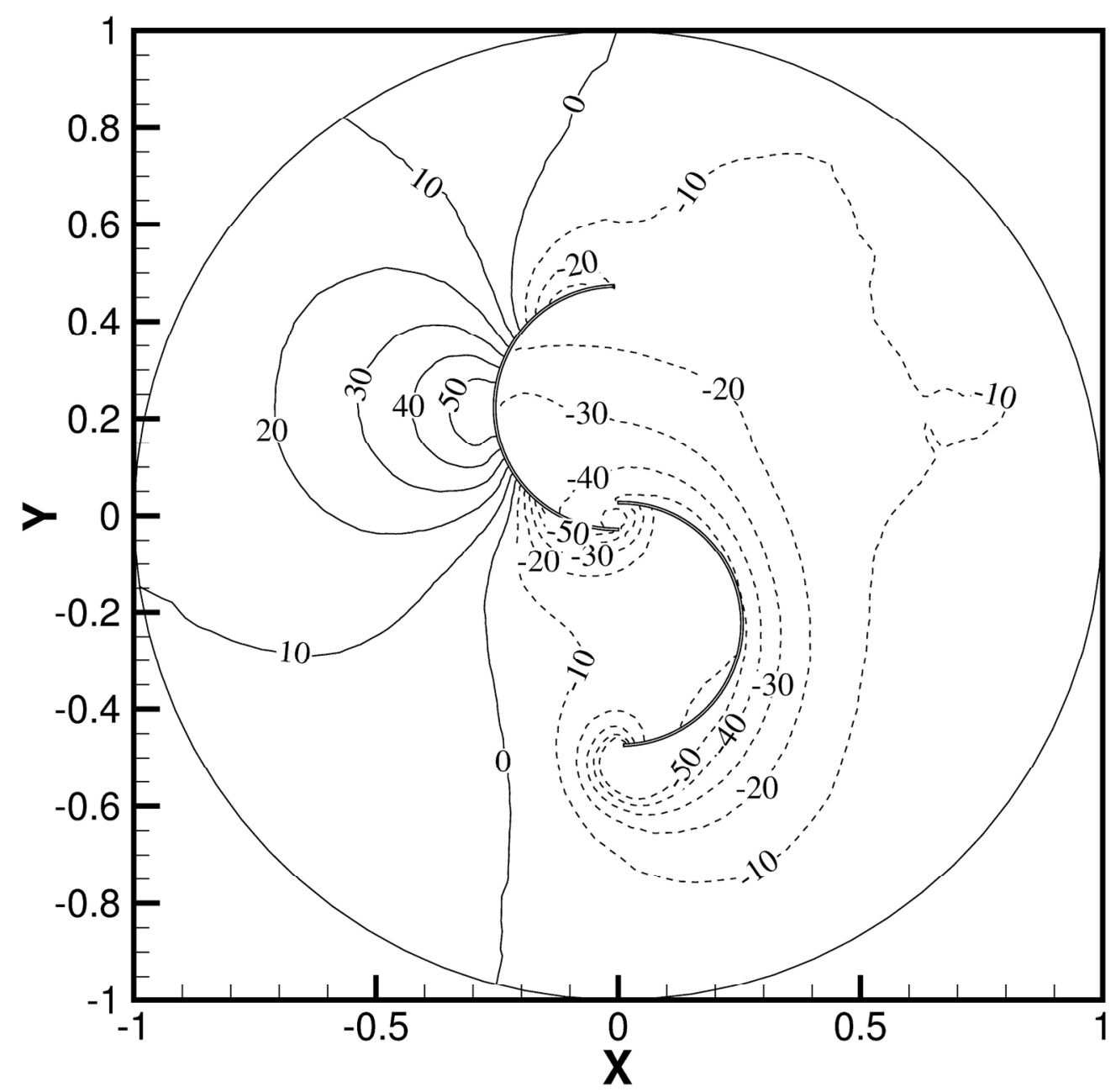

Figure9b

$169 \times 167 \mathrm{~mm}(300 \times 300$ DPI $)$ 


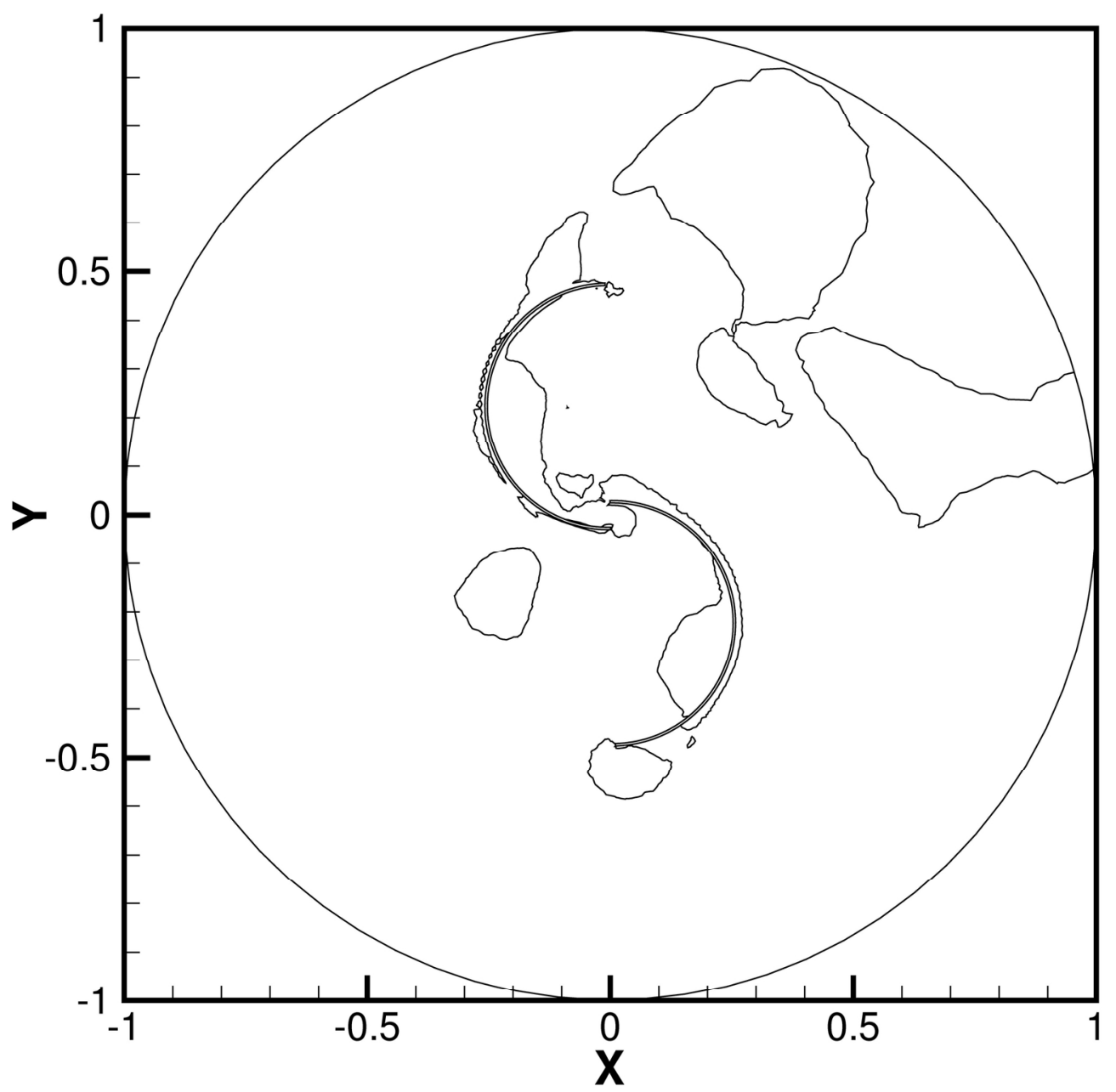

Figure9c

$171 \times 168 \mathrm{~mm}$ (300 x 300 DPI) 


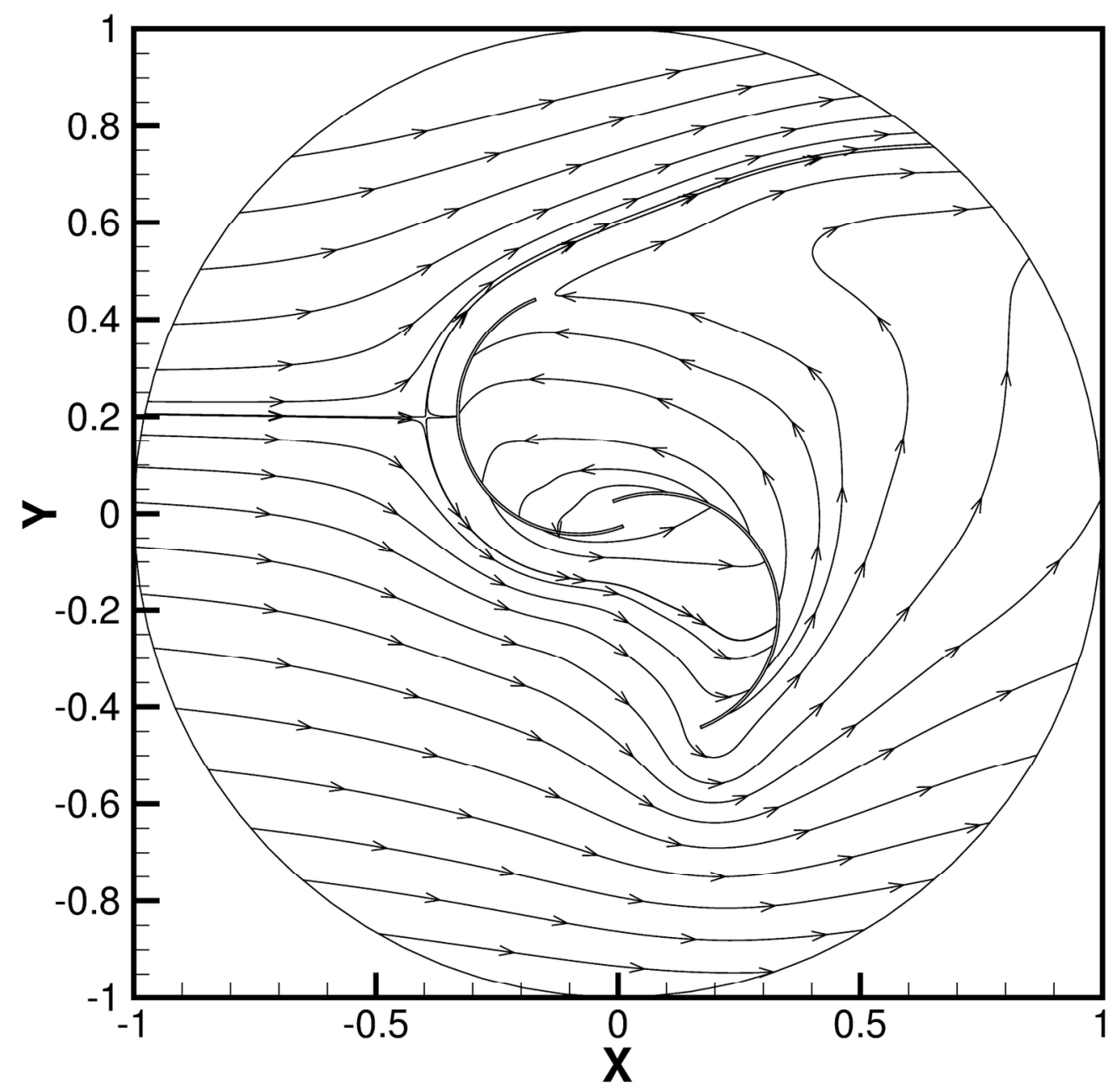

Figure9d

$170 \times 167 \mathrm{~mm}$ (300 x 300 DPI) 


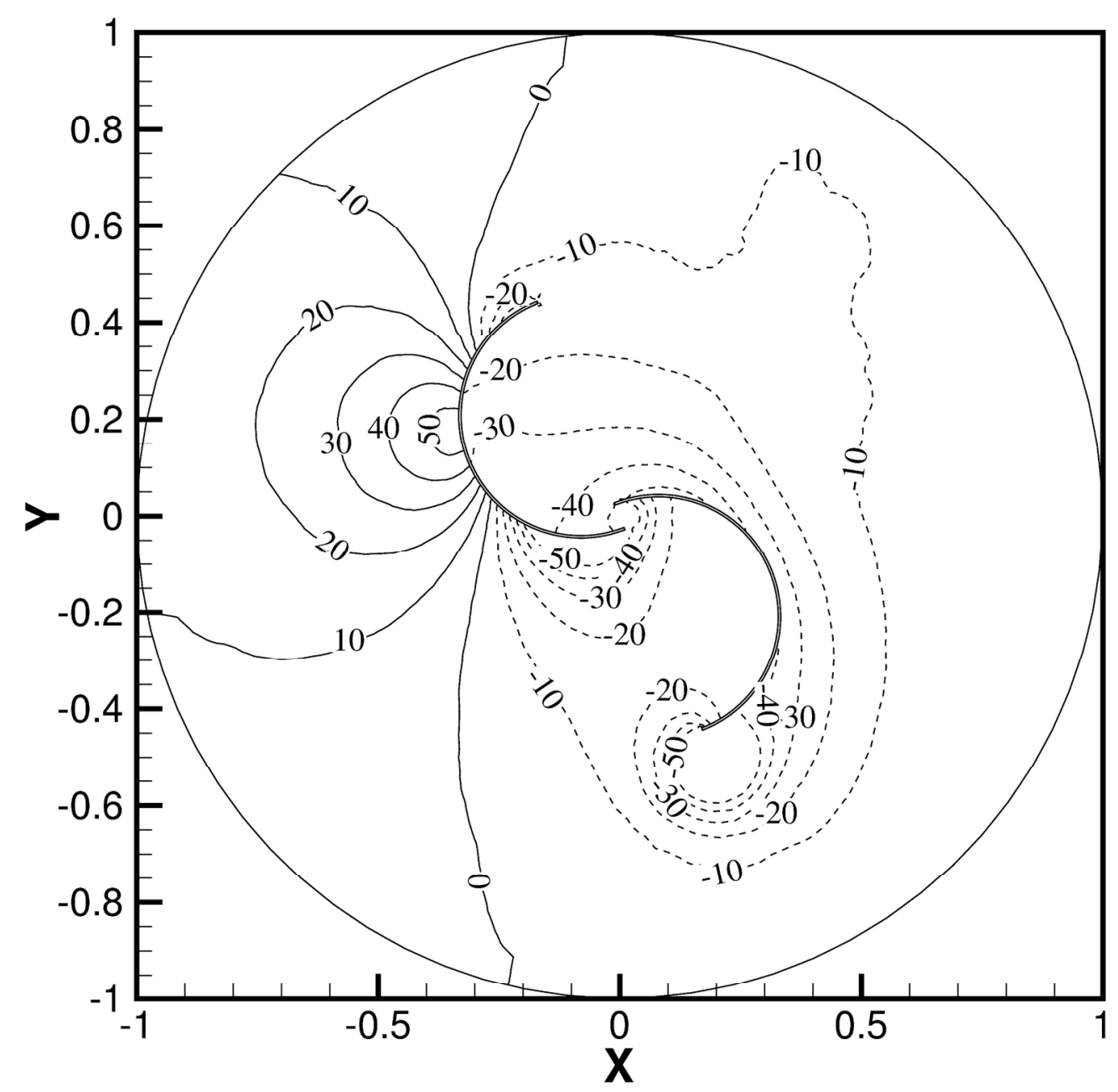

Figure9e

$170 \times 167 \mathrm{~mm}(300 \times 300 \mathrm{DPI})$ 


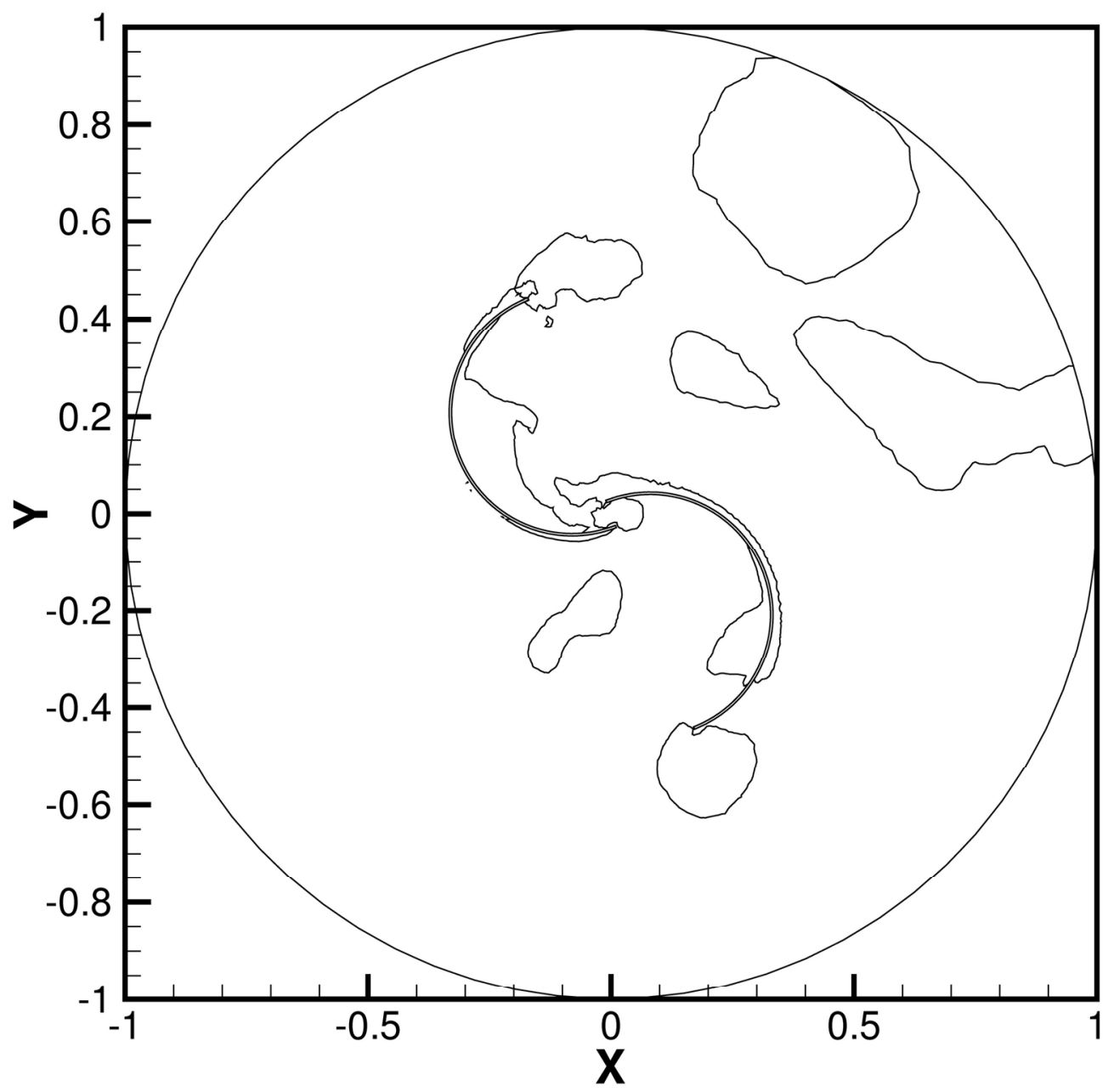

Figure9f

$171 \times 168 \mathrm{~mm}(300 \times 300 \mathrm{DPI})$ 


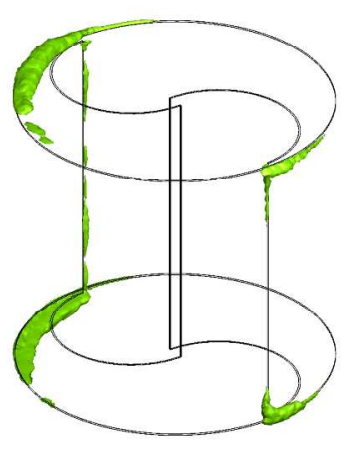

$\lambda_{2}=-8000$

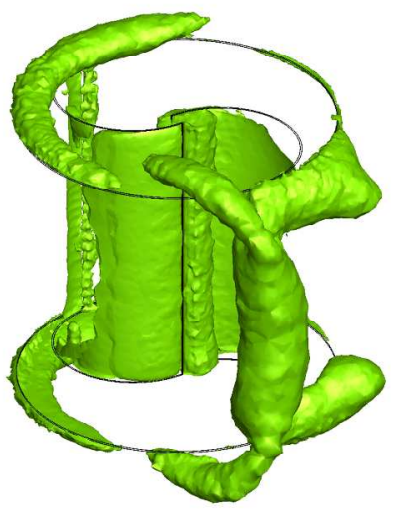

$\lambda_{2}=-600$

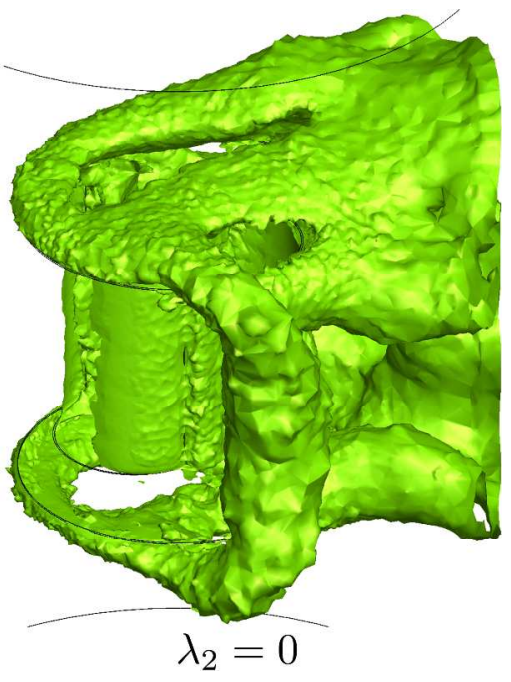

Figure 10

$361 \times 183 \mathrm{~mm}$ (300 x 300 DPI) 